\title{
Psychometric properties of the Social Interactions Questionnaire (SIQ) in an older adult sample
}

\author{
Kimberly Debra Kalish \\ West Virginia University
}

Follow this and additional works at: https://researchrepository.wvu.edu/etd

\section{Recommended Citation}

Kalish, Kimberly Debra, "Psychometric properties of the Social Interactions Questionnaire (SIQ) in an older adult sample" (2001). Graduate Theses, Dissertations, and Problem Reports. 1438.

https://researchrepository.wvu.edu/etd/1438

This Dissertation is protected by copyright and/or related rights. It has been brought to you by the The Research Repository @ WVU with permission from the rights-holder(s). You are free to use this Dissertation in any way that is permitted by the copyright and related rights legislation that applies to your use. For other uses you must obtain permission from the rights-holder(s) directly, unless additional rights are indicated by a Creative Commons license in the record and/ or on the work itself. This Dissertation has been accepted for inclusion in WVU Graduate Theses, Dissertations, and Problem Reports collection by an authorized administrator of The Research Repository @ WVU.

For more information, please contact researchrepository@mail.wvu.edu. 
Psychometric Properties of the Social Interactions Questionnaire (SIQ) in an Older Adult Sample

Kimberly D. Kalish

\begin{abstract}
Dissertation submitted to the College of Arts and Sciences at West Virginia University in partial fulfillment of the requirements for the degree of
\end{abstract}
Doctor of Philosophy
in Psychology

Barry A. Edelstein, Ph.D., Chair Stan Cohen, Ph.D.

Kevin Larkin, Ph.D. Rick Briggs, Ed.D. Philip Comer, Ph.D.

Department of Psychology

Morgantown, West Virginia 2001

Keywords: Older Adults, Negative Social Interactions, Social Support, Assessment Copyright 2001 Kimberly D. Kalish 


\begin{abstract}
Psychometric Properties of the

Social Interactions Questionnaire (SIQ) in an Older Adult Sample
\end{abstract}

Kimberly D. Kalish

This study examined the psychometric properties of the Social Interactions Questionnaire (SIQ; Kalish \& Edelstein, 1996), a quick and efficient tool to measure negative social interactions. Overwhelming evidence has emerged over the past decade indicating that negative social interactions (NSIs) are strongly related to measures of mental and physical health. A critique of existing measures of NSIs reveals long and cumbersome interviews that are comprised of some, but not all, of the critical elements of NSIs. The SIQ efficiently measures these critical elements, which include a) perceived versus structural components of NSIs, b) seven different types of NSIs, c) overall relationship style (e.g., reciprocal, overprotective), d) nature of the relation between the respondent and the support provider (e.g., spouse, friend), and e) the specific stressor experienced by the respondent (e.g., retirement, care-taking). The present study included interview and questionnaire data from a sample of 106 idependently living older adults. Results provide evidence for the construct validity of the SIQ by revealing significant correlations in the expected directions with two measures of mental health including the Beck Depression Inventory (BDI; Beck et al., 1961) and the Life Satisfaction Index (LSI-Z; Wood et al., 1969). Further evidence for SIQ construct validity is found in the significant relation between the SIQ and the Frequency of Interactions Inventory (FII; Stephens et al., 1987), another measure of negative social interactions. Evidence for temporal stability is evidenced in the relation between data from initial administration of the SIQ and retest data at 2 days and 2 weeks. Internal consistency of the SIQ is also strongly supported. It is concluded that the SIQ is a psychometrically sound instrument that incorporates all of the critical elements necessary to sufficiently examine NSIs, and can be administered more quickly and efficiently than existing measures. The SIQ is a valuable tool for clinical assessment and further examination of SIQs. Suggestions for future research are presented. 


\section{Acknowledgments}

First and foremost, my appreciation goes to Barry Edelstein, the chair of this dissertation for his patience, support, and exemplary guidance. He remains my role model professionally and among the kindest and most admirable men I know. My thanks go also to my committee members, Stan Cohen, Rick Briggs, Kevin Larkin, and Phil Comer. They patiently stood by this project for several years. Their suggestions and expertise improved both this project and my professional skills. It has been delightful to work with each of them.

The data collection, which took three years to complete, was made possible by the assistance and generosity of my dear aunt, Mrs. Lillian Briskin and my mother, Gail Packard. I would still be slowly trudging forward on this project without their help. My mother's assistance stretches far beyond data collection. She helped by scheduling interviews, watching my children, and believing in me every step of the way. There are no words to express my appreciation.

I thank my husband, Dave for his patience and assistance and my sons both of whom were born during this project. Thank you Jacob for understanding every time I left the house to collect data, or work on "mommy's big game" instead of playing with you. Thank you Max for being a perfect little boy even though you lived through all of my stress in utero as I completed analyses and defended my dissertation.

I thank my grandfather, Ephraim Jacob Kauffman who made me a star before I ever accomplished anything, who would have been so pleased to call me "doc," and who believed so strongly in education, saying, "they can take a lot away from you, but they can never take away the things you've learned." My family has made it all worthwhile. I cherish them and thank them for standing by me.

Finally, this dissertation is proudly dedicated to Gail Packard. Every accomplishment is so much sweeter when it's shared with you. 


\section{Table of Contents}

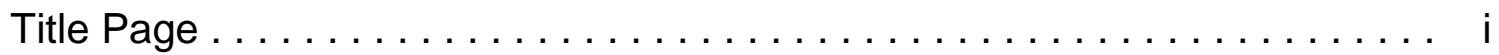

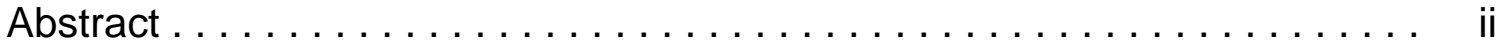

Acknowledgments. .................... iii

Table of Contents $\ldots \ldots \ldots \ldots \ldots \ldots \ldots \ldots \ldots \ldots \ldots \ldots \ldots \ldots \ldots \ldots$ iv

List of Tables .......................... vi

List of Appendices $\ldots \ldots \ldots \ldots \ldots \ldots \ldots \ldots \ldots \ldots \ldots \ldots \ldots \ldots \ldots \ldots \ldots \ldots \ldots \ldots$

Introduction $\ldots \ldots \ldots \ldots \ldots \ldots \ldots \ldots \ldots \ldots \ldots \ldots \ldots \ldots \ldots \ldots \ldots \ldots \ldots \ldots$

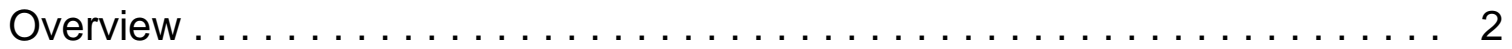

Harmful Effects of Negative Social Interactions . . . . . . . . . 2

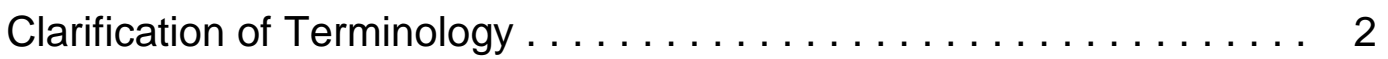

Critical Components of Negative Social Interactions ........... 3

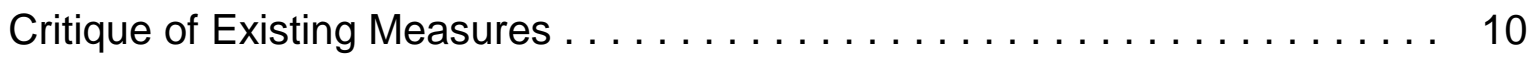

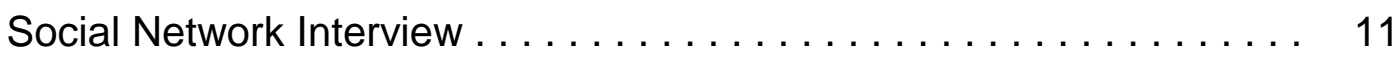

Negative Social Ties . . . . . . . . . . . . . . . . . . . . . 13

Problematic Social Ties and Exchanges ................. 14

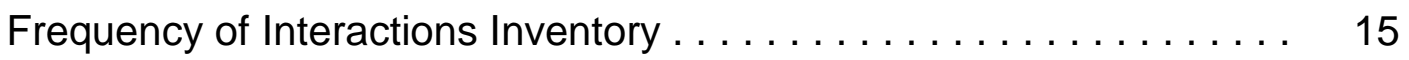

Social Support Structural Interview . . . . . . . . . . . . . . . 17

Overprotection Scale for Adults . . . . . . . . . . . . . . . . . 17

Aspects of Personal Networks. . . . . . . . . . . . . . 18

Arizona Social Support Interview Schedule . . . . . . . . . . . . 19

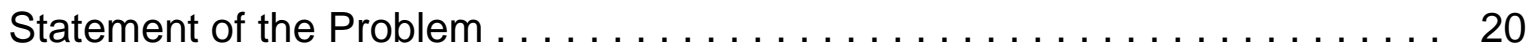

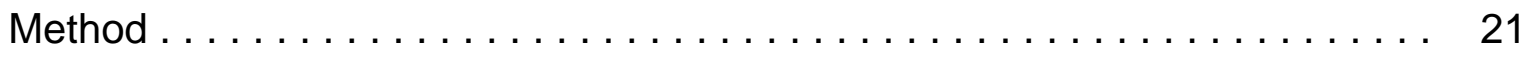

Participants ......................... 21

Measures ............................. 22

Statistical Analyses . . . . . . . . . . . . . . . . . . . 28

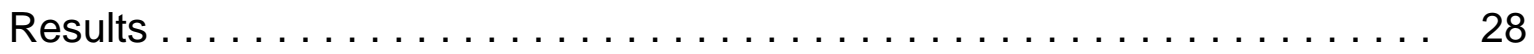

Convergent Evidence of Construct Validity . . . . . . . . . . . . 29

Reliability ......................... 32

Discussion .......................... 33 


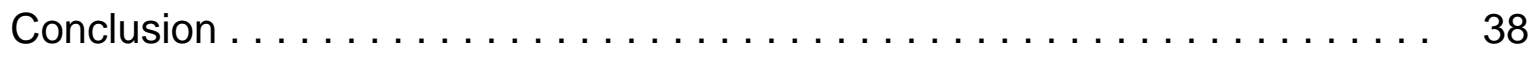

Future Research . . . . . . . . . . . . . . . . . . . . 39

References . . . . . . . . . . . . . . . . . . . . . 41

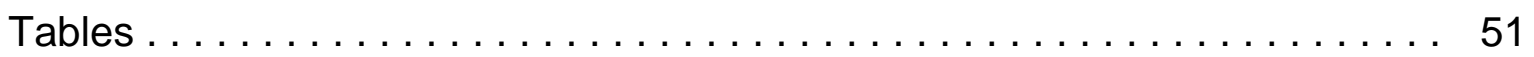

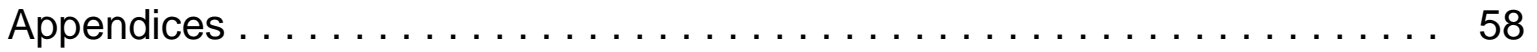

Resume ........................... 75 


\section{LIST OF TABLES}

Table 1 Examples of Findings for Studies Examining Specificity of Need . . 51

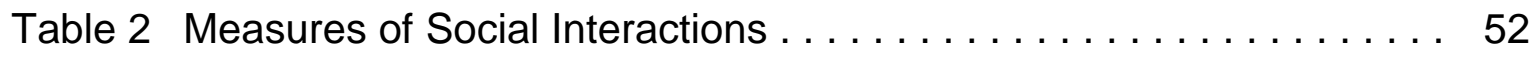

Table 3 Frequency Table of Demographic Variables ............... 54

Table 4 Descriptive Statistics: Means of Demographic Variables by Endorsement of Stressors . . . . . . . . . . . . . . . . 55

Table 5 Descriptive Statistics . . . . . . . . . . . . . . . . . . . 56

Table 6 Correlations: Relation between Original SIQ and Retest Data . . . 57 


\section{LIST OF APPENDICES}

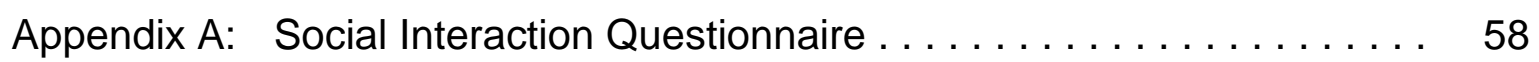

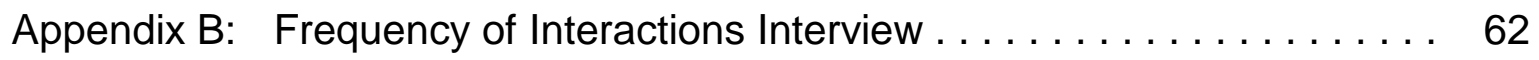

Appendix C: Demographics Questionnaire . . . . . . . . . . . . . . 67

Appendix D: Contact Form . . . . . . . . . . . . . . . . . . 69

Appendix E: Correlations: SIQ and Measures of Mental Health (BDI \& LSI) 71

Appendix F: Correlations: Relation between SIQ and FII . . . . . . . 73 
Psychometric Properties of the Social Interactions Questionnaire (SIQ) in an Older Adult Sample

Social interactions have long been studied by researchers and touted to have a positive impact on mental and physical health in older adults (Hanson \& Carpenter, 1994). More recently, researchers have begun to examine the harmful side of social interactions, referred to as negative social interactions (NSIs), and have found that NSIs have a deleterious effect on health in older adults (Coyne, Wortman, Lehman, 1988; Rook, 1997). These findings have been produced with overwhelming reliability. Unfortunately, it is difficult to compare findings between studies because researchers have used several different instruments to measure NSIs. In a recent review of 14 studies examining the impact of NSIs in older adults, nine different instruments were used. Each of these instruments examined different aspects of NSIs, many were unreliable, based upon the subjective nature of the instrument, and most were extremely time-consuming for both the interviewer and the participant. In addition, most of these instruments were created specifically for the research projects in which they were first published and lack significant psychometric data, if any. Furthermore, the nature of these time consuming and subjective instruments virtually precludes the use of these instruments for clinical practice. Finally, no one instrument currently used to measure NSIs, measures all of the factors of NSIs found to be critical in the literature.

The problem, therefore, is that despite the importance of the measurement of NSIs for both research and clinical work, there is no efficient and comprehensive measure of NSIs with established psychometric properties currently available. The purpose of this study is to examine the psychometric properties of the Social Interactions Questionnaire (SIQ), a self-report instrument that is both efficient and comprehensive in that it measures all of the components identified in the literature as contributors to negative social interactions. The following sections will address two primary questions: (a) what are the critical components to measure when examining NSIs? and (b) how well 
do existing measures examine these components? First, an overview of the social interaction literature will be presented to familiarize the reader with important distinctions and terms related to the social interaction literature and to illustrate the critical components of NSIs. Second, the existing instruments used to examine NSIs will be critiqued to reveal their strengths and weaknesses. Third, the SIQ will be presented and its psychometric properties will be examined.

\section{Overview}

\section{Harmful Effects of Negative Social Interactions}

For the purpose of this paper, NSIs include any interpersonal event or relationship in which the participant is in some way hurt by or dissatisfied with the interaction. Such interactions do appear to have a deleterious effect on health. Recent examinations suggest a strong correlation between NSIs and decreased mental health (e.g., Rook, 1984), reduced physical health (Cicirelli, 1990), and increased dependent behaviors (e.g., Baltes \& Silverberg, 1994) in older adults. In addition, the literature has consistently revealed that deleterious effects of NSIs on health are greater than beneficial effects of positive social interactions (e.g., Finch, Okun, Barrera, Zautra, \& Reich, 1989; Helgeson, 1993; Krause, 1995; Okun, Melichar, \& Hill, 1990; Rivera, Rose, Futterman, Lovett, \& Gallagher-Thompson, 1991). There is also evidence that NSIs and positive social interactions occur independently (i.e., they are not correlated, Finch et al., 1989; Okun et al., 1990; Rook, 1984). Since (a) NSIs may pose a serious threat to the physical and mental health of older adults and (b) NSIs are significantly related to health independently of positive social interactions, it is important that researchers attend to the negative side of social interactions.

\section{Clarification of Terminology}

The current terminology used in the literature obscures the important distinction between NSIs and positive social interactions. The term social support, is often used to describe all social interactions (e.g., Jennison, 1992; Potts, Hurwicz, Goldstein, \& Beranovic, 1992). Given that all social interactions are not supportive, other researchers have more accurately used the terms 
social interaction (e.g., Schuster, Kessler, \& Aseltine, 1990), social exchange (e.g., Rook, 1987), or interpersonal contact (e.g., Norris, Stephens, \& Kinney, $1990)$ to refer to social interactions. In the interest of consistency and clarity, the following definitions will be used for the remainder of this paper: (a) negative social interaction (NSI) will refer to all harmful or unfavorable interactions, (b) positive social interaction (PSI) will be used in reference to all supportive or favorable interactions, (c) social interaction will refer to general interpersonal exchanges and (d) network member will be used to refer to any individual with whom social interactions occur, whether these interactions are positive or negative.

\section{Critical Components of NSIs}

Perceived vs. structural components of NSIs.

In the examination of NSIs, researchers have focused either on the perceived or the structural aspects of NSIs. Perceived measures, also termed subjective or qualitative, examine one's perceived quality of interactions (e.g., how upsetting, helpful, enjoyable, or reliable the respondent judges the network member to be) (Rook \& Dooley, 1985; Schaefer, Coyne, \& Lazarus, 1981). Subjective aspects of social interactions are often difficult to measure because the respondent's learning history, mental health, and the desire to provide socially desirable responses may confound both perceptions and reports (Bolger \& Eckenrode, 1991). Nevertheless, several researchers have found that subjective evaluations of interactions are more strongly related to health and are more salient predictors of health variables than are objective measures (Cohen, Sherrod, \& Clark, 1986; Kaniasty \& Norris, 1992; Krause, 1995a).

In contrast, structural measures of social interactions, also termed objective or quantitative measures, involve the measurement of observable aspects of one's social network (e.g., number of people in one's social network, number of interactions with specific individuals, number of interactions during a specified time period). For example, in an illustrative study using a structural model, researchers found that long-term psychiatric patients, as opposed to "normal" individuals, have smaller social networks, and fewer interactions within 
these shrunken networks, suggesting that decreased social supports are related to poorer mental health (Cresswell, Kuipers, \& Power, 1992). In another example of a quantitative model used to measure the impact of social interactions, Carstensen and colleagues found that that the overall quantity of people in one's social network decreases with age and quantity of "emotionally close" people in one's social network increases with age (Carstensen, 1992; Carstensen \& TurkCharles, 1994; Lang \& Carstensen, 1994). In an effort to clarify the terms used, the following review is offered as a guide. The words "perceived," "subjective," and "qualitative" all describe information regarding one's perceptions an interaction in terms of quality, enjoyment, or helpfulness. The terms "structural," "objective," and "quantitative" refer to measures of interaction that can be observed or counted such as the number of network members or the frequency of interactions.

In summary, there is evidence that subjective perceptions of interactions relate more strongly to mental and physical health variables than do structural measures (Helgeson, 1993; Schaefer et al., 1981). There is also evidence that perceived and structural components of NSIs exist independently of one another (e.g., number and quality of interactions are unrelated) (Rook, 1984). Although perceived measures of NSIs have been found to be more strongly related to mental health in older adults, several researchers have found a relation between structural measures of NSIs and mental health. As a result, a comprehensive measure of NSIs should examine both perceived and structural elements of social interactions.

Several types of NSIs.

There are several different types of social interactions, each satisfying different functions. The social interaction literature is replete with myriad labels for different types of interactions. Some of these labels are defined inconsistently or overlap with each other depending upon the citation. Within this section, the most common types of interactions will be presented, followed by a discussion of the effects (i.e., positive or negative) of different types of interactions depending upon the situation and the source. 
Familiarity with several types of interactions will assist the reader in understanding the critique of the assessment measures and the rationale for selecting certain types of interactions for measurement in the SIQ. Tangible support (also called material aid or physical assistance) describes any interaction in which a concrete service is provided (e.g., help with chores, providing transportation, financial assistance). Cognitive guidance (also called advice or informational support) includes the dissemination of information on a topic that is unclear or upsetting (e.g., legal advice, medical options). Socializing (also called social participation or intimate interaction) involves interactions in which the purpose is to share a potentially enjoyable situation (e.g., sharing a meal, taking a walk, playing a game). Emotional support (also called positive feedback or esteem support) provides a sense of being heard and cared about (e.g., listening, reflecting, reporting concern). Self-disclosure includes interactions that provide a comfortable non-judgmental environment in which to reveal private information, feelings, and thoughts (e.g., discussing dissatisfaction with medical care, fear of illness). The above mentioned definitions have been compiled from several articles (Fiore, Becker, \& Coppel, 1983; Revenson, Schiaffino, Majerovitz, \& Gibofsky, 1991; Rivera et al., 1991; Rotenberg \& Hamel, 1988). In a review of the social interaction literature, Rook (1994) reported that many of the above mentioned types of interactions are not significantly different in their impact on older adults. She suggested that they may be categorized more efficiently into only three categories: emotional, instrumental, and informational interactions. As a result, all of the types of social interactions that are found in the literature need not be assessed to produce a good study according to Rook. Rook reports that assessing the emotional, instrumental, and informational interactions is sufficient because these factors comprise three theoretically distinct factors.

Despite the fact that all factors have not been systematically examined for their unique variance in their impact on mental health, it is important to assess for more than one type of interaction. There is reason to believe that different 
types of interactions have variable effects depending upon the situation and the source. These issues will be addressed in the following section.

Recent literature suggests that types of interactions (i.e., tangible, emotional, cognitive guidance) are not equal in their impact on mental health. That is, a "specificity of need" exists, meaning that different types and sources of support are helpful for different types of stressors (Dean, Kolody, \& Wood, 1990; Steinbach, 1992). The literature examining specificity of need in older adults suggests that different types of interactions affect older adults differently depending upon the stressor experienced (e.g., illness, financial strain, Russell \& Cutrona, 1991). The findings of a representative sample of studies examining the differing impact of various types of interactions in the presence of various stressors can be found in Table 1. The studies represented in table 1 were chosen because each of these studies involved the examination of one's response to a specific stressor. As is illustrated in the table, no overwhelming trends emerge. For example, in one study emotional support was found to be helpful for individuals with a serious illness, and tangible support was helpful for individuals with non-life threatening illnesses (i.e., cancer, Martin, Davis, Baron, Suls, \& Blanchard, 1994). In another study, emotional support was helpful for people with minor concerns and tangible support was not (Cutrona, Cohen, \& Ingram, 1990). Yet another study revealed that tangible and emotional support are both helpful for serious illness (Friedman \& King, 1994). It is difficult to compare studies because they all measure different dimensions of NSIs (e.g., cognitive guidance, emotional support). However, the common denominator of these findings is that different types of interactions do result in significantly diverse effects depending upon the stressor. As a result, rigorous researchers of social interactions must assess different dimensions of social interactions in light of a given stressor, rather than obtaining one global measurement of PSIs or NSIs.

In summary, since there are so many different types of social interactions, a comprehensive measure of NSIs must assess the critical types of social interactions discussed in the above review. Unfortunately, the literature 
examining the impact of different types of social interactions in light of different stressors is equivocal. As a result, the present study examines the types of social interactions found most commonly in the literature, including (1) emotional, (2) instrumental/tangible, (3) informational interactions, and (4)socializing. The present study also assesses for current stressors experienced by the respondent in order to further examine the unanswered question, which types of support are most effective in light of a given type of stressful situation?

Overall relationship style.

Unlike the previous discussion that focused on the type of interactions within the relationship (e.g., tangible support, socializing), this section focuses on the relationship as a whole. Three global relationship types may exist: (a) reciprocal, where both parties give and receive support to the other, (b) overprotective, where one member of the relationship receives more care and assistance than he or she needs or wants, and (c) exploitative, where one member of the relationship is taken advantage of by the other. There is reason to believe that overall characteristics of the relationship (e.g., reciprocal, overprotective, exploitative) have a significant impact on the mental health of older adults (Rook, 1987). There is evidence that reciprocal relationships are associated with better mental health than are relationships in which one member receives substantially more support or provides the majority of support (e.g., Bornstein, 1995; Jung, 1990; Krause, 1986, 1995; Roberto \& Scott, 1986; Rotenberg \& Hamel, 1988).

When older adults receive more support than they provide, they may begin to feel "overprotected." Overprotection often leads to feelings of guilt, dependency, and incompetence, which may foster physical or cognitive decline and negatively impact mental health (Coyne et al., 1988; Kaplan \& Toshima, 1990; Shinn, Lehmann, \& Wong, 1984). This assumption is consistent with literature examining the importance of personal control over one's own life. For example, Langer and Rodin $(1976,1977)$ showed that nursing home residents who were given the responsibility of controlling their environment (e.g., how to arrange their room, what do to with their time) and a plant to care for, lived longer 
and reported being happier than residents whose environments were controlled by staff and whose plants were cared for by staff members. The importance of personal control over one's own environment has also been conceptualized in the "learned helplessness" literature (Seligman, 1975). The negative effects of overprotection are exacerbated by the fact that the helper may experience anxiety or may feel overwhelmed or unappreciated, which may result in resentment and negative interactions with the older adult (Coyne et al, 1988). In such a scenario, overprotection functions as an NSI, both by taking away the older adults' control over his or her environment, and by introducing upsetting interactions (criticizing and arguing).

In exploitative relationships, older adults may provide more support than they receive in a relationship. For example, Krause (1986) reported that the depressive effects of bereavement on older adults are exacerbated when the older adult is called upon to support others rather than receive support for his or her grief. Being responsible for others may result in feeling overwhelmed or unappreciated (Reynolds, Remer, \& Johnson, 1995; Talbott, 1990).

In summary, reciprocal relationships are more beneficial than either overprotective or exploitative relationships. Researchers of social interactions should determine the overall climate of the relationship (e.g., overprotective, reciprocal) when assessing social interactions. The discussion presented above, reveals that the examination of the overall climate of the relationship is an essential component in a measure of social interactions. Due to the importance of the overall climate of the relationship, the SIQ assesses the level of reciprocity, overprotection, and exploitation.

Relationship with support provider.

The relationship between the older adult and the person with whom he or she is interacting, may impact whether the interaction is seen as positive or negative. Two relatively consistent findings have emerged in the social support literature involving the relationship with the support provider. The first is that older adults tend to interact with family more than they interact with friends (Anotnucci \& Akiyama, 1987; Carstensen, 1992; Krause, 1995a, Wilson, Calsyn, 
Orlofsky, 1994). The second is that family members tend to be more strongly associated with negative interactions than are friends (Krause, 1995a; Morgan, 1989; Rook, 1990). Within family relationships, older adults tend to have problematic interactions with spouses more frequently than with siblings (Norris et al., 1990). In summary, older adults tend to interact more often with family than with friends and interactions with family members tend to be more upsetting than interactions with friends. With these findings in mind, it is important to examine the source of social interactions when examining social interactions. The NSI examines the relationship of the respondent with his or her social network members.

\section{Current stressor.}

Current stressors must be measured in an assessment of social interactions for two reasons. The first is that, as discussed earlier in this paper, evidence exists suggesting that different types of stressors require different types of support. The second reason is that social interactions seem to have a greater impact on mental health when the individual is under stress (Ingersoll-Dayton, Morgan, \& Antonucci, 1997; Morgan; 1989; Kiecolt-Glaser, Dyer, \& Shuttleworth, 1988).

In summary, several aspects of NSIs need to be measured in order to examine all of the critical factors that could contribute to NSIs. These components include (a) subjective (e.g., quality of interactions) and structural (e.g., frequency of interactions) aspects of the interaction, (b) several types of NSIs (e.g., tangible, emotional), (c) overall perception of the relationship (e.g., overprotective, reciprocal), (d) participant's relation to the network member (e.g., spouse, adult child, grandchild, friend), and (e) current stressor or stressors in the older adult's environment.

\section{Critique of Existing Measures}

Several instruments have been used to measure NSIs in older adults. Since there is no "gold standard" in the assessment of NSIs, researchers have typically used any of a number of pre-existing assessment tools or developed their own instruments. Although some assessment tools are used more 
frequently in the research than others, no one tool is prominent. Instruments of NSIs vary in terms of structure (e.g., interview, questionnaire), the conceptual model with which the instrument was designed (e.g., subjective, structural), and the specific types of social interactions measured (e.g., tangible, emotional). Many measures of NSIs are long, open-ended, and difficult to quantify, further complicating the task of comparing results from two different studies even when the same tool was used. See Rook (1994) for a more thorough discussion of instruments used to measure NSIs in older adults. Within this section, selected instruments used to measure NSIs in older adults are critiqued. Instruments included in this critique have been used to measure NSIs in older adults. Instruments that are specific to certain diagnosis or illnesses are not included in this critique because the goal is to identify elements that are critical in a measure of NSIs for older adults in general. For example, Rauktis, Koeske, and Tereshko's Negative Social Interactions Scale (1995) is not included because it assesses NSIs specific to caretakers (e.g., how often do people make insensitive comments about X's disease). The Arthritis Specific Social Support Scale (Revensen \& Majerovits, 1992; Revensen \& Schiaffino, 1990) is also excluded from this critique because it is designed to be used specifically with individuals with illness (e.g., gives feedback about the way individuals cope with pain, goal is to change the way the individual copes with his or her illness). The critique of each instrument will include (a) a description of the instrument, (b) available psychometric data (though very little psychometric data are available), (c) a summary of findings obtained with an older adult population, and (d) a discussion of the strengths and weaknesses of the instrument. The purpose of the critique is to identify strengths and weaknesses of existing instruments so that the best features of each instrument may be compiled and the least critical features may be eliminated in an effort to create a better, comprehensive measure of NSIs. The primary findings discussed below are illustrated in Table 2.

Social Network Interview (SNI) 
Description. The Social Network Interview (SNI; Fiore et al., 1983; adapted from Hirsch, 1980) requires several days of data collection by the participant and several hours, over the course of at least two interviews on the part of the both the interviewer and the participant. The first step of the SNI is to take several days to create a comprehensive list of people in the participant's social network and then rate them on scale from 0 (closest) to 100 (most distant) according to how close the participant feels to each network member.

Participants then choose the 15 people in their list to whom they feel closest, and make daily ratings on each network member in a variety of areas of social interactions, for a week. At the end of the week, the participant returns to the experimenter, who conducts an interview on the ten people rated as closest to the participant.

The experimenter tries to ensure that interactions with at least one problematic network member is examined by including a network member rated as problematic even if that person is not identified as one of the top ten closest to the participant. If no one is identified as problematic, the interviewer includes the network member rated most distant from the participant. The purpose of this selection process is to obtain a well-rounded assessment of the participant's social interactions.

Based on open-ended, questions, the interviewer subjectively rates each network member on a 6-point scale, regarding how helpful and upsetting they are in the context of five different areas of social interactions including: (a) socializing, (b) tangible assistance, (c) cognitive guidance, (d) emotional support, and (e) self-disclosure. As each of these five areas receive both a helpful and an upset rating, each network member for each participant receives 10 different ratings. The interview was designed to produce one helpful rating and one upset rating for each participant by calculating the mean ratings across all ten network members for each participant.

Available psychometric data. Negative social interaction scores accounted for $34 \%$ of variance in depression scores and different types of NSIs (socializing, tangible support, cognitive guidance, emotional support. self-disclosure) were 
significantly positively correlated with depression scores $(r=.36$ to $r=.54)$. Scores on this instrument have also been found to be unrelated to scores on the Crowne and Marlowe social desirability scale.

Findings. This instrument was used in three of the fourteen studies reviewed (Fiore at al., 1983, Kiecolt-Glaser et al., 1988, \& Pagel, Erdly, \& Becker, 1987). The following major findings were found with the SNI: (a) NSIs and positive social interactions are not related (Fiore et al., 1983; Kiecolt-Glaser et al., 1988); (b) NSIs predict depression better than positive social interactions (Fiore et al., 1983 ;1988; Pagel et al., 1987); (c) cognitive guidance is strongly negatively related to depression levels (Fiore et al., 1983); (d) both subjective and objective measures of NSIs are positively related to depression (Fiore et al., 1983, Kiecolt-Glaser et al., 1988). These findings suggest that it is important to measure both objective and subjective measures of NSIs and that it is useful to measure specific types of NSIs.

Strengths and weaknesses. The SNI is a good measure of NSIs in that it measures both subjective and objective dimensions of social interactions (e.g., 6-point rating of perception of helpfulness and upset, the number of individuals within the participant's social network) and it examines five components of social interactions (e.g., socializing, tangible assistance, cognitive guidance, emotional support, self-disclosure). However, the instrument is clearly too long and cumbersome to be implemented regularly, it requires too much effort from participants over a long time period, and scoring is subjective and often leading. In addition, limited psychometric data are available on this instrument. Furthermore, the instrument fails to measure the overall climate of the relationship (e.g., reciprocal, overprotective), the participant's relation to the network member, and the degree and type of stressors that the participant is experiencing.

Negative Social Ties

Description. The Negative Social Ties Interview (NST; Finch et al., 1989; adapted from Fischer, 1982) consists of fourteen items assessing social interactions. Ten items identify social network members associated with different 
types of helpful instrumental social interactions (e.g., assisting with household tasks, engaging in social activities, advising on important decisions, lending money,) and helpful emotional social interactions (e.g., listening to worries, providing a sense of stability and closeness, sharing happiness, providing comfort). Four items identify social network members associated with upsetting interactions (e.g., criticizing behavior, taking advantage, being unreliable, provoking feelings of conflict or anger). Objective scores are obtained by summing the number of people associated with each of the different types of social interactions.

Available psychometric data. The authors report good internal consistency with an alpha of .79. In addition, the instrument's NSI scores positively correlated with depression in three different trials $(r=.16$ to $r=.24)$.

Findings. This instrument was used in two of the fourteen reviewed studies (Finch et al., 1989; Finch \& Zautra, 1992). The important findings obtained while using this instrument are that (a) NSIs are significantly related to mental health (positively related to depression and negatively related to wellbeing) (Finch et al., 1989; Finch \& Zautra, 1992); (b) NSIs and positive social interactions are not related to each other (Finch et al., 1989); and (c) social interactions are more strongly related to mental health measures in participants with more stress in their lives (Finch et al., 1989). These results indicate that objective measures of social interactions should be measured and that current stressors are an important factor in the measurement of social interactions.

Strengths and weaknesses. One strength of the NST is that it measures several aspects of social interactions (e.g., instrumental, emotional, and upsetting). Several weaknesses exist in the NST. It measures only structural aspects of social interactions, and it fails to measure both the overall perception of the relationship (e.g., reciprocal, overprotective) and the participant's relation to the network member. In addition, though a relation was found between degree of stress and impact of social interactions, the NST does not assess participant's current stressors.

Problematic Social Ties and Exchanges (Rook, 1984) 
Description. The Problematic Social Ties and Exchanges interview (PST; Rook, 1984; adapted from Fischer, 1982) requires participants to list individuals in their social networks who satisfy any of the five following problems: (a) invade privacy, (b) take advantage, (c) break promises, (d) provoke feelings of anger, and (e) provide a consistent source of problems. Three structural measures of NSIs are obtained. First, for each of the five problems listed, a score of 0 is assigned if no network members are listed and a 1 is assigned if one or more network members are listed. These numbers are then summed, resulting in a range of $0-5$. The second and third NSI ratings include the number of people who provide exclusively NSIs and the frequency of NSIs. The frequency rating is obtained by having participants rate on a scale of 1 (once a year or less) to 6 (daily or several times per week) how often they interact with problematic individuals. It should be noted that this measure is used in conjunction with a parallel measure that obtains three structural scores for supportive social ties. In addition, a rating is obtained involving individuals who provide both supportive and problematic social interactions (number of individuals and frequency of interactions).

Available psychometric data. Negative social interactions scores, when measured with the PST, were found to be significantly negatively related to psychological well-being (Beta $=-.0256), F(1,99)=7.81, p \leq .01$.

Findings. While using the Problematic Social Ties and Exchanges (PST) interview along with the Supportive Social Ties and Exchanges interview, Rook (1984) found that (a) NSIs were not related to positive social interactions, and (b) number of network members who provided NSIs was positively correlated with improved mental health.

Strengths and weaknesses. Some strengths of the PST are that it measures several aspects of NSIs (criticizing, breaking promises, invading privacy, provoking feelings of anger), it allows for a rating of the overall perception of the relationship (who is a consistent source of problems?), and the quantitative nature of the instrument allows for easy scoring and increases the likelihood of inter-rater reliability (no data are provided on reliability). Some 
weakness of the PST are that it measures only structural (not subjective) aspects of social interactions and it does not measure the participant's relation to the network member or the participant's current stressors.

Frequency of Interactions Inventory (Stephens, Kinney, Norris, \& Ritchie, 1987)

Description. The Frequency of Interactions Inventory (FII; Stephens et al., 1987; adapted from Fischer, 1982) is a 20-item interview designed to assess structural and subjective aspects of positive and negative social interactions. Participants report the number of network members that provide certain types of interactions over the past two months. Ten types of interactions are presented. Three questions are asked regarding instrumental interactions (e.g., "is there someone who has proved not to be dependable in running errands", "has assisted you in personal care activities when you would have preferred to have done these things by yourself", "has assisted you in other activities of daily living when you would have preferred to have done these things by yourself"). Seven questions are presented that examine expressive interactions ("is there someone who has said or done something that made you feel more worried and upset", "has given you information that made you feel more upset and worried", "has given you unwanted advice about how you should change your ways of doing everyday activities", "has said or done something that has discouraged you from getting better", "seems unable to share feelings with you", "has said or done something to make you feel uncomfortable about the way you look", and "is there someone who has an illness similar to your own who did not make you feel more comfortable with your own feelings?"). The positive aspects of all of these items are asked to assess positive social interactions (e.g., "is there someone who helped you by running errands?"). The following information is then obtained about each social network member listed in the 19-item interview: (a) age, (b) his or her relationship with the respondent, (c) frequency of interactions with the respondent (on a five point scale). Subjective information is also obtained from the respondent about his or her perceived (a) satisfaction with the relationship, (d) closeness to the network member, and (c) importance of the relationship. All subjective ratings are obtained on a 4-point scale. 
Available psychometric data. The portion of the FII measuring NSIs correlates negatively with mental health. The test-retest reliability after a oneweek delay is $r=.77$. Inter-rater reliability was reported to be adequate, though data were not provided. An internal consistency estimate yielded an alpha of 67 .

Findings. The FII has been used with stroke survivors. Negative and positive social interactions were found to be unrelated to each other (Stephens et al., 1987; Norris, Stephens, \& Kinney, 1990), NSIs have been found to predict personal adjustment following stroke, and NSIs are better predictors of ADL independence than positive social interactions (Norris Stephens, \& Kinney, 1990).

Strengths and weaknesses. The FII has several strengths. It measures both instrumental and expressive social interactions, it measures overprotectiveness (although it is not scored to utilize this measure), it obtains both subjective and structural aspects of social interactions, and it measures the participants' relation to the network member. The FII fails to measure the participant's current stressors and their overall perception of whether the relationship is reciprocal or exploitative. In addition, the interview nature of the measure requires time (close to an hour) by both the participant and the interviewer.

\section{Social Support Structural Interview}

Description. The Social Support Structural Interview (SSSI; Okun et al., 1990; adapted from the Children's Inventory of Social Support; CISS, Wolchik, Sandler, \& Braver, 1987) is an interview designed to measure structural aspects of positive and negative social interactions. Participants are asked to list the people who are both helpful and upsetting in relation to assistance with (a) advice and information, (b) goods and services, (c) emotions, and (d) positive or negative feedback.

Available psychometric data. The only information available is that NSI scores were positively correlated with psychological distress scores $(r=.42$, $\mathrm{p} \leq .001)$. In addition, NSIs accounted for $17 \%$ of the variance in psychological distress. 
Findings. Using the SSSI to measure NSIs, Okun et al. (1990) found that NSIs and positive social interactions were negatively correlated, and NSIs had a strong positive relation with psychological distress.

Strengths and weaknesses. The SSSI measures several types of social interactions (e.g., emotional, tangible, cognitive guidance, self-disclosure, socializing). However, this instrument measures structural aspects of interactions while failing to measure subjective aspects of interactions, the overall perception of the relationship, the participant's relation to the network member, and the participant's current stressors.

\section{Overprotection Scale for Adults}

Description. The Overprotection Scale for Adults (OPSA; Thompson, Sobolew-Shubin, Graham, \& Janigian, 1989; adapted from the Parental Bonding Instrument; PBI, Parker, Tupling, \& Brown, 1979) is a 7-item questionnaire designed to measure older adults' perceptions of being overprotected (e.g., sometimes those around me treat me like a small child, the people around me try to overprotect me, the people around me want me to be dependent on them). Respondents answer questions on a 4-point scale ranging from 1 (strongly disagree) to 4 (strongly agree).

Available psychometric data. The internal consistency reliability of the OPSA is reported to be high with an alpha of .88. The convergent validity has been demonstrated by moderate correlation between the OPSA and the Parental Bonding Instrument $(r=.63)$. Discriminant validity has been demonstrated by the fact that the OPSA is not significantly related to quantity of social support.

Findings. Using the OPSA, overprotection has been found to be positively related to depression in older adults (Thompson \& Sobolew-Shubin, 1993a, 1993b) measured with both the Center for Epidemiologic Studies--Depressed Mood Scale (CES-D) and the Geriatric Depression Scale (GDS).

Strengths and weaknesses. Some strengths of the OPSA include the fact that it obtains a subjective measure of NSIs and it measures an overall perception of interactions (overprotection). Some weaknesses of the instrument include its failure to obtain objective measures of NSIs, types of NSIs other than 
overprotectiveness, the participant's relation to the network member, and current stressors in the participant's environment.

Aspects of Personal Networks

Description. The Aspects of Personal Networks (ASPN; Morgan, Neal, \& Carder, 1997) is an interview designed to measure structural aspects of positive and negative social interactions. Respondents list members of their social networks who have a positive or negative impact on their lives in the areas of informational support (advice and information), emotional support (emotions and feelings), and instrumental support (things that need to be done). The number of network members providing each type of interaction is tallied, resulting in three scores for positive social interactions and three scores for NSIs.

Available psychometric data. A regression analysis revealed that NSIs accounted for a significant amount of variance in depression scores (percentages were not reported) in three different cohorts (e.g., first, second, and third year following bereavement), when interacting with various sources (e.g., friends, family).

Findings. In a study by Morgan and colleagues (1997), NSIs were not related to positive social interactions, NSIs accounted for greater variance in depression levels than did positive social interactions, and NSIs occurred more frequently from family members than friends.

Strengths and weaknesses. The ASPN has several strengths. It measures several types of social interactions (e.g., informational, emotional, instrumental), it measures the respondent's relation to the social network member, and it obtains a structural measure of social interactions. The ASPN fails to measure subjective aspects of social interactions, the overall perception of the relationship, and the respondent's current stressors.

Arizona Social Support Interview Schedule

Description. The Arizona Social Support Interview Schedule (ASSIS: Barrera, Sandler, \& Ramsay, 1981) is an interview designed to obtain several ratings of social interactions. Respondents are asked to list people who are likely to provide support on seven categories of social interactions (intimate 
interactions, material aid, advice, physical assistance, positive feedback, social participation, and negative interaction). Participants then report which individuals actually provided support over the past month. Finally, participants are asked to report their perceived need and their perceived satisfaction with received support in each of the seven areas.

Available psychometric data. The test-retest reliability coefficient after a 2-day delay was .882. The authors reported good internal consistency for two different administrations of the instrument, with alphas at .926 and. 940. In addition, both perceived and structural NSI scores were significantly positively related to depression scores $F(1,163)=4.73, p \leq .05$ and $F(1,163=5.21, p \leq$ $.05)$, respectively.

Findings. In a study examining older adult, female caregivers, Rivera and colleagues (1991) found that both frequency and quality of NSIs were related to depression. They found that NSIs were more strongly related to depression than were positive social interactions.

Strengths and weaknesses. Some strengths of the ASSIS are that it measures both subjective and structural aspects of the interaction and it measures several types of social interactions. The ASSIS does not measure the participant's overall perception of the relationship, the participant's relation to the network member, or the current stressors existing in the participant's environment.

\section{Summary}

The above critique of selected measures of NSIs illustrates the fact that many measures of NSIs exist, all with their own strengths and weaknesses, but no one measure encompasses all of the identified elements necessary to tap the critical components of social interactions. The reader now has a familiarity of the instruments available for assessing NSIs in older adults. An instrument designed to assess the critical components of social interactions is clearly needed.

\section{Statement of the Problem}

Much is known about the harmful impact of NSIs. For example, they are associated with measures of mental health and they are not related to positive 
social interactions. Much is yet to be discovered. For example, we have yet to learn which network members are more likely to be associated with NSIs for any given stressor, what interventions would reduce the deleterious effects of NSIs, and the nature of the most harmful interactions. An essential tool in the further examination of NSIs is a relatively brief, standardized, assessment instrument with sound psychometric properties with which to measure NSIs. Unfortunately, as was illustrated in the above critiques, NSIs have not been adequately measured because none of the existing measures of NSIs address all of the critical elements of NSIs. In addition, the existing measures tend to be long and cumbersome for both the researcher and the participant. Consequently, the purpose of this research is to examine the psychometric properties of the Social Interactions Questionnaire (SIQ; Kalish \& Edelstein, 1996), a NSI assessment instrument, that will be described in the method section.

The construct validity of the SIQ was examined through convergent evidence. The relations between SIQ scores and scores on conceptually related measures of mental health were examined. In addition, the relations between SIQ scores and scores on another measure of NSIs was examined to support the concurrent validity of the SIQ. Temporal stability was examined by administering the SIQ on two different dates to 40 (37.7\%) participants. Twenty (18.9\%) SIQs were re-administered two days after the initial administration and $20(18.9 \%)$ questionnaires were re-administered 2 weeks after initial administration.

\section{Method}

\section{Participants}

One hundred and six community dwelling older adults aged 60 or older served as research participants. Age of participants ranged from 61 to 96 , with a mean age of 81 . Eighty-four (79.2\%) of participants were female and 22 were male. Level of education ranged from 7 to 21 years with a mean of 14 years of schooling. Fifty-five participants (51.9\%) were widowed, 37 (34.9\%) were married, 9 (8.5\%) were single, and 5 (4.7\%) were divorced. Sixty-seven participants (63.2\%) lived alone, 35 (33\%) lived with their spouse, $2(1.9 \%)$ lived 
with a sibling, and $2(1.9 \%)$ lived with a roommate. Ninety-eight participants $(92.5 \%)$ were retired and 8 were employed $(7.5 \%)$. Ninety-nine participants (93.4\%) were Caucasion, 2 (1.9\%) were Indian, 2 (1.9\%) were Filipino, 1 (0.9\%) was African American, 1 (0.9\%) was Latino American, and 1 (0.9\%) was Asian American. Forty-five participants (42.5\%) rated their health as average, 39 $(36.8 \%)$ rated their health as better than average, $11(10.4 \%)$ rated their health as excellent, $9(8.5 \%)$ rated their health as worse than average, and $2(1.9 \%)$ rated their health as poor. Some participants were related to one another in the form of spouses and siblings.

A frequency table describing demographic variables can be found in Table 3. Descriptive demographic data are presented in Table 4, to provide demographic information on the participants who endorsed various stressors. It is beyond the scope of this paper to examine the relation between specific stressors and the perception of negative social interactions. Therefore, the descriptive table alone is presented and may be addressed further in future publications.

Participants were recruited from medical clinics, apartment buildings, and senior living communities through the use of flyers and word-of-mouth.

Participants were able to read and understand all questionnaires as evidenced by reading aloud and explaining the content of the consent form. As an incentive for participation, all participants were entered into a drawing from which they were eligible for two chances to win $\$ 50.00$. Treatment of all participants and questionnaire data complied with guidelines prescribed in "Ethical Principles: In the Conduct of Research with Human Participants" (APA, 1982).

\section{Measures}

\section{Negative Social Interactions.}

Social Interaction Questionnaire (SIQ). The SIQ (see Appendix A) is a questionnaire that was developed by the author for a previous study (Kalish \& Edelstein, 1996). It was modified and improved upon for this project. The SIQ is a comparatively brief questionnaire that was developed by incorporating the most salient features of other measures of social interactions into one 
questionnaire. The SIQ measures the following components of NSIs: (a) quantitative aspects of social interactions, including total number of network members, frequency of interactions, and the number of social network members associated with various types of interactions, obtained by tallying the number of individual's identified in participants' social networks, (b) qualitative aspects of social interactions, assessed by asking participants to rate, on a 6-point Likert scale, how helpful or upsetting specific interactions were perceived to be, (c) four different types of social interactions (e.g., socializing, tangible assistance, cognitive guidance, and emotional support), (d) the participant's overall perception of the relationship (overprotective, reciprocal, exploitative), rated on a 6-point Likert scale, (e) the relation between the participant and the person with whom he or she interacted (e.g., friend, spouse), and (f) current stressors in the participant's environment.

The SIQ contains elements of the most critical features noted in the negative social interaction literature. The critique of existing measures, as presented earlier in this document, reveals that several aspects of social interactions are important and significantly related to measures of mental health. Each of these salient features was selected for representation in the SIQ and is described below.

The SIQ was adapted primarily from Fiore and colleagues' Social Network Interview (SNI; 1983). Both the SIQ and the SNI utilize a 6-point scale to obtain subjective measures of social interactions. In addition, similar types of interactions are assessed (socializing, tangible assistance, cognitive guidance, and emotional support). An item is taken from Thompson and Soblew-Shubin's Overprotection Scale for Adults (OPSA; 1993a, 1993b), in which respondents are asked to rate how overprotective they find the relationship. Additional information regarding the $\mathrm{SNI}$ and OPSA can be found both in the discussion above and in Table 2. Two additional items were added to the SIQ to assess the overall reciprocity of the relationship and whether the relationship is seen as exploitative (i.e., does the participant feel taken advantage of). These items were included in the SIQ due to the importance of these factors in terms of mental 
health and overall relationship satisfaction (e.g., Bornstein, 1995; Jung, 1990; Krause, 1986, 1995; Roberto \& Scott, 1986; Rook, 1987; Rotenberg \& Hamel, 1988).

All positive and negative responses were averaged separately, resulting in a total composite mean negative score and a total composite mean positive score. In addition, scores for each of the 7-areas examined were tallied separately, both by average quality of positive and negative interactions and total number of network members perceived as being associated with positive or negative interactions for each type of interaction. Any individual rated at least moderately (4-6) helpful or moderately upsetting for any given type of interaction was added to the tally of positive or negative individuals for that item. Individuals rated less than moderately helpful or upsetting (i.e., those receiving scores from 1-3) were not included in the tally of either positive or negative network members for that type of interaction.

The inventory of stressful events presented with the SIQ is an informal instrument intended to provide an overview of the stressful events experienced by the individual within the past 6 months. This inventory contains 11 stressful events. Participants were asked to indicate whether the events occurred in the past 6 months. If the event occurred, the respondent specified how long ago the event occurred. There is room on the questionnaire for participants to list other stressful events that may not have been included on the measure. The items in the inventory of stressful events used with the SIQ were adapted from the Life Events Questionnaire (LEQ; Brugha \& Cragg, 1990), with some items added and others deleted. The stressful events added to the LEQ for this study included (a) moving to a new home, (b) moving to a new town, and (c) becoming the caretaker of a spouse. These items were added because of the increased likelihood of these events occurring for an elderly population. A question about retirement replaced questions about unemployment and being "sacked" from a job due to the high frequency of retirement in the population sampled. The original LEQ has high sensitivity and low specificity, being likely to falsely identify non-stressful events as stressful. The LEQ has a test-retest reliability of .84 at 3 
months. Concurrent validity, as evidenced by the relation between respondent reports and reports by a significant other is quite good ( $90 \%$ agreement). There are no psychometric data available on the inventory of stressful events used in the present study with the SIQ because it is a modification of the LEQ for the purpose of the present study.

Frequency of Interactions Inventory (FII). The FII (Stephens et al., 1987), as discussed earlier in the critique section, is a 20 item interview designed to assess structural and subjective aspects of positive and negative social interactions (see Appendix B). Participants were asked to report the names of individuals with whom they have certain types of interactions. Additional questions were then asked about network members listed during the 19-item interview. Information was obtained on the total number of network members, frequency of interactions, and total number of network members associated with positive and negative instrumental and expressive interactions. Since participants are asked only to list individuals associated with each type of positive and negative interactions, and no rating is assigned to the individual, all network members listed were tallied to produce a total number of network members associated with a given type of interaction. Perceived closeness, importance, and satisfaction with each overall relationship was rated on a 4-point Likert-scale. Psychometric properties are discussed in the critique section of this document.

Mental Health.

Beck Depression Inventory (BDI). The BDI (Beck, Ward, Mendelson, Mock, \& Erbaugh, 1961) is a 21 -item, self-report depression inventory presented in questionnaire format. Respondents chose which of four statements, for each item, best applied to them over the past week. The original intent of the BDI was not to be used as a screening device. Rather, it was intended to measure the severity of depression, once depression has been diagnosed (Kendall, Hollon, Beck, Hammen, \& Ingram, 1987). However, the BDI has been found to be both valid and reliable in its ability to screen whether older adults meet Research and Diagnostic Criteria for depression (Gallagher, Nies, \& Thompson, 1982; 
Pachana, Gallagher-Thompson, \& Thompson, 1994). The BDI was selected for this study for several reasons. It is brief and easy to administer. The BDI accurately classifies older adults as depressed or non-depressed (Wolfe, Morrow, \& Fredrickson, 1996). It is both well-known and easily obtainable, which lends itself to clinical and replication applications. Due to its excellent psychometric properties, the BDI is recommended for use with older adults with one exception. The exception is that cognitively impaired elders may have difficulty with the 4-choice response format, which requires some retention of information (Pachana et al., 1994). This concern was not a factor in the present study because the sample included independently living older adults who were able to comprehend and recall the information presented.

Life Satisfaction Index (LSI-Z). The LSI-Z (Wood, Wylie, \& Sheafor, 1969), a 13-item questionnaire, was developed by revising Neugarten, Havinghurt, and Tobin's Life Satisfaction Scales (1961). The LSI-Z was designed to measure psychological well-being in the elderly. It's psychometric properties have been explored in several studies using older adult samples (e.g., Abraham, 1992; Adams, 1969; Burckhardt, Woods, Schultz, \& Ziebarth, 1989; Kozma \& Stones, 1988; Wood, Wylie, \& Sheafor, 1969). Participants were required to answer 13 questions about life satisfaction on a 3-point Likert Scale. The LSI-Z is scored by assigning two points to all of the "agree" responses for items 1, 2, 4, $5,7,8,9$, and 12, two points for all of the "disagree" responses for items $3,6,10$, 11 , and 13, and one point for all "not sure" responses. These numbers are then summed, resulting in a range of scores from 0 to 26 . The LSI-Z has been shown to be valid for differentiating between high (26) and low (0) levels of life satisfaction. Split-half reliability is .79 in an older adult sample (Wood et al., 1969). Test-retest reliability was found to be .80 to .90 in a sample of 227 ill, middle aged, and older adults (Burckhardt et al., 1989). The LSI-Z was found to correlate with another measure of life satisfaction (Quality of Life Scale; Flanagan, 1978) with coefficients ranging from .67 to .75 during three different test periods (Burckhardt et al., 1989). In addition, scores on the LSI were found to correlate significantly with results from an NSI measure used by Rook (1984). 
The LSI was selected for this study particularly because it has been found to be a valid measure of life satisfaction in older adults. The measurement of life satisfaction in conjunction with a measurement of depression provides a fuller picture of participants' overall mental health than measuring depression only. Finally, the LSI has been successfully used in another study examining social interactions (Rook, 1984), which provides an opportunity for comparison of results of this study with a previous findings.

Demographic Questionnaire. A demographic questionnaire was used to determine age, gender, marital status, level of education, living situation (e.g., alone, with spouse), number of family members living within a 1-hour drive radius from the respondent (e.g., children, grandchildren, other relatives), ethnicity, employment status, education, and self-perceived health of the respondent (see Appendix C).

Procedure

Informed consent was obtained for all participants. All participants were individually administered the SIQ, FII, BDI, LSI-Z, and demographic form in their own homes or at a public clinic. Half of the participants were administered the FII before the SIQ and the other half were administered the SIQ prior to the FII. All other questionnaires were administered in a random order. All measures were administered by the primary researcher. Participants were given an additional copy of the SIQ in an unsealed, self-addressed, stamped envelope to complete either 2 days later or 2 weeks later, and mail back to the researcher. Assignment to the 2-day versus 2-week group was done by alternating from one participant to the next unless a participant requested to be in the 2-day or 2-week group. Participants were called by the investigator to prompt them to return their questionnaires if they agreed to receive such a call. Several participants agreed to make an appointment to meet with the investigator at the 2-day or 2-week response time. This was done to increase response rate for follow-up data. When requested, the investigator wrote responses to questionnaire items for participants due to poor vision or trembling hands. Participants completed a contact form (Appendix D) and were entered into a random drawing in which 
they had two chances to win $\$ 50.00$. Every participant, whether they chose to complete the questionnaires or not, was given a small gift of candies.

\section{Statistical Analysis}

Means and standard deviations are reported for all measures. To explore convergent evidence of SIQ construct validity, the relations between SIQ scores (total NSI score, scores for each of the seven types of NSIs) and scores on the two measures of mental health (BDI and $\mathrm{LSI}$ ) were examined with a multiple correlation analysis. To address the question of convergent evidence of SIQ construct validity by examining the relation between the SIQ and the FII (Stephens et al., 1987) another measure of NSIs, a second correlational analysis included objective scores (total number of network members, average frequency of interactions, the number of network members associated with positive and negative experiences in a variety of types of interactions) and subjective scores (overall perceptions of social interactions including overprotection, exploitation, and reciprocity on the SIQ and closeness, importance, and satisfaction on the FII). To examine temporal stability, as evidenced by the relation between initial administration of the SIQ and re-test data (at 2-days and 2-weeks), Pearson Product Moment correlation analyses were conducted. To examine internal consistency, coefficient alpha was calculated.

\section{Results}

The results will be presented in three parts. First, means, standard deviations, and ranges for all primary dependent and independent measures and quantitative demographic variables including age and education of the respondent were calculated and can be found in Table 5. Second, convergent evidence of construct validity of the SIQ will be presented. Finally, reliability will be discussed in terms of temporal stability and internal consistency of the SIQ. Frequency data for nominal demographic data including gender, marital status, living situation, ethnicity, employment status, and self-perceived health have been described in the methods section and can be found in Table 3. 


\section{Convergent Evidence of Construct Validity}

Relations between the SIQ and other measures of mental health. Two correlation analyses were conducted. The first included scores from the LSI, BDI, and negative social interaction scores for each of the seven components of the SIQ. This correlation matrix shows the degree of the relation between negative components of the SIQ and two measures of mental health (e.g., BDI \& LSI). Results from the analysis can be found in Appendix E. As illustrated in Appendix $E$, convergent evidence of construct validity of the SIQ is seen in the positive correlation between overall average NSI scores on the SIQ and BDI scores $(r=.397, p \leq .01)$ and the negative correlation between overall average NSI scores and LSI scores $(r=.-217, p \leq .05)$. These results suggest that as interactions are perceived as more negative or unpleasant, depression levels increase and life satisfaction levels decrease. When examining the specific components of the $S I Q, B D I$ scores were positively correlated with scores reflecting negative social experiences (e.g., socializing; $r=.383, p \leq .01$ ), negative experiences related to tangible assistance (e.g., chores, rides, financial assistance; $r=.324, p \leq .01$ ), negative experiences related to emotional support (e.g., sympathy, caring, understanding; $r=.239, p \leq .05$ ), and scores reflecting how exploited a person feels in the overall relationship (e.g., how much they feel taken advantage of; $r=.241, p \leq .05)$. LSI scores were negatively related to unpleasant social experiences $(r=-.260, p \leq .01)$, indicating that life satisfaction decreases as social experiences become more unpleasant. The relation between the SIQ and both the BDI and LSI was similar to relations between NSIs and other measures of mental health in the literature (e.g., Finch et al., 1989; Fiore et al., 1983).

Relations between the SIQ and another measure of social interactions. The second correlation analysis included both subjective and objective variables of the SIQ and FII. Objective variables included (a) total number of network members, (b) average frequency of interactions, (c) total number of network members associated with both negative and positive interactions, (d) total number of network members associated with positive and negative social, tangible, cognitive, and emotional interactions as measured in the SIQ and (e) 
total number of network members associated with positive and negative instrumental and expressive interactions as measured on the FII. Subjective variables on the SIQ included the average ratings of how reciprocal, overprotective, and exploitative interactions were perceived to be. Subjective variables on the FII included average ratings of how close, important, and satisfying relationships were perceived to be.

The correlation matrix representing the relation between objective and subjective variables on the SIQ and FII can be found in Appendix F. The total number of cases represented in each presented relation is not always 106 because $100 \%$ of participants did not endorse each type of positive and negative interaction. As illustrated in Appendix F, convergent evidence of construct validity is supported in the significant relations between the SIQ and FII. The total number of network members listed in the SIQ was positively correlated with the total number of network members listed in the FII $(r=.549, p \leq .01)$, the average frequency of interactions as reported on the SIQ and FII were positively correlated $(r=.456, p \leq .01)$, and the total number of individuals associated with positive social interactions on the SIQ and FII were related $(r=.361, p \leq .01)$.

The number of individuals associated with unpleasant socializing interactions on the SIQ was positively related to the number of unpleasant expressive interactions on the FII $(r=.282, p \leq .05)$. The number of individuals associated with pleasant socializing interactions on the SIQ was positively related to the number of positive instrumental interactions on the FII $(r=.280$, $p \leq .05)$ and positive expressive interactions on the FII $(r=.391, p \leq .01)$.

The number of individuals associated with positive tangible interactions on the SIQ was positively correlated with the number of individuals associated with positive instrumental $(r=.260, p \leq .05)$ and expressive interactions on the FII $(r=.277, p \leq .01)$. The number of individuals associated with negative cognitive guidance on the SIQ was positively correlated with unpleasant expressive interactions on the FII $(r=.248, p \leq .05)$.

The number of individuals associated with positive emotional interactions on the SIQ was positively correlated with the number of individuals associated 
with positive instrumental $(r=.319, p \leq .05)$ and positive expressive $(r=.381, p \leq .01)$ interactions on the FII.

Significant correlations were found among subjective variables as well. The average score indicating how reciprocal a relationship was perceived to be on the SIQ was positively correlated with how close $(r=.305, p \leq .01)$, important $(r=.315, p \leq .01)$, and satisfying $(r=.367, p \leq .01)$ the relationship was perceived to be on the FII. The perception of being exploited or "taken advantage of" on the $S I Q$ was negatively related to ratings of perceived closeness $(r=-.301, p \leq .01)$, importance $(r=-.379, p \leq .01)$, and satisfaction $(r=-.471, p \leq .01)$ of the relationship on the FII.

Surprisingly, some of the structural measures of the SIQ and FII correlated significantly in the opposite direction expected. The number of individuals associated with positive socializing experiences on the SIQ was positively correlated with the number of individuals associated with unpleasant expressive interactions on the FII $(r=.354, p \leq .01)$. The number of network members associated with negative tangible interactions on the SIQ was positively correlated with the number of network members associated with positive expressive interactions on the FII ( $r=.238, p \leq .05)$. The number of individuals associated with positive tangible interactions on the SIQ was positively correlated with the number of individuals associated with negative instrumental $(r=.621, p \leq .01)$ and expressive $(r=.355, p \leq .01)$ interactions on the FII. The number of network members associated with positive cognitive guidance on the SIQ was positively correlated with the number of individuals associated with negative expressive interactions on the FII ( $r=.338, p \leq .01)$. Finally, the number of network members associated with positive emotional interactions on the SIQ was positively correlated with the number of network members associated with negative expressive interactions on the FII $(r=.311, p \leq .01)$. Reliability

Temporal stability. A Pearson Product Moment correlation analysis revealed the relation between the original administration of the SIQ and the 
retest of the SIQ (see Table 6). Twenty participants completed the SIQ 2 days after the original administration of the questionnaire, and 20 participants completed the SIQ 2 weeks after the initial administration. All 15 components of the SIQ were included when examining temporal stability (e.g., total number of supports, frequency of interactions, average perceptions of overall positive and negative social interactions, and positive and negative perceived measures of socializing, tangible support, cognitive guidance, emotional support, exploitation, overprotection, reciprocity). Evidence for temporal stability is presented in Table 6. As illustrated in Table 6, all 15 components of the SIQ correlated significantly with the same components when comparing first and second administration of the measure.

Correlation coefficients were high (>.80) in the areas of total number of social supports, perceived positive social interactions, perceived positive socializing interactions, perceived positive cognitive guidance, perceived positive emotional interactions, and perceptions of overprotection for both 2-day and 2week follow-up data. Correlations were also high (>.80) for 2-day retest data for perceived positive tangible interactions, and perceived negative cognitive guidance. Correlations were high (>.80) for 2-week retest data for frequency of interactions, perceptions of overall negative interactions, perceived negative tangible interactions, perceived negative emotional interactions, and perceptions of exploitation and reciprocity. Correlation coefficients were comparatively lower for 2-day retest data for frequency of interactions $(r=.778)$ perceived overall negative social interactions ( $r=.694)$, perceived negative socializing interactions at 2-days ( $r=.515)$ and 2-weeks ( $r=.789)$, perceived positive tangible interactions at 2-weeks $(r=.574)$, perceived negative tangible interactions at 2-days $(r=.689)$, perceived negative cognitive guidance at 2-weeks ( $r=.575)$, and perceived negative emotional interactions ( $r=.607)$, exploitation ( $r=.613)$, and reciprocity $(r=.639)$ at 2-days. Test-retest relations were similar to test-retest data in the NSI literature (e.g., Stephens et al., 1987).

Internal consistency. The internal consistency of the SIQ was examined by calculating coefficient alpha, yielding a coefficient of .85 . Internal consistency 
data for the SIQ are similar to internal consistency data reported for other measures of NSI in the literature (e.g., Barrera et al., 1981; Finch et al., 1989; Stephens et al., 1987).

\section{Discussion}

The results from this investigation indicate that the SIQ has promising psychometric properties and that it is a useful tool for measuring social interactions. A discussion of the findings will address the psychometric properties of the NSI.

\section{Psychometric Properties of the SIQ}

Convergent evidence of validity. Evidence for the construct validity of the SIQ was found by establishing that the SIQ correlates in the expected direction with two conceptually related measures of mental health and one measure of social interactions. As expected, results of the present study indicate that as negative interactions are perceived as more problematic, as evidenced by scores on the SIQ, depression scores increase and life satisfaction scores decrease.

The relation between the SIQ and FII were investigated to gather convergent evidence for the construct validity of the SIQ. Since these measures are not identical, but are similar in that some of the same constructs are measured, it was expected that structural variables measured in both measures including total number of network members and average frequency of interactions would be positively correlated. It was further anticipated that variables measuring perceptions of interactions on the SIQ (social, emotional, tangible, cognitive, overprotection, exploitative, reciprocal) would be related to perceived measures of interactions on the FII (overall closeness, importance, and satisfaction). As predicted, some significant correlations were found between structural and perceived measures of the SIQ and FII, suggesting that there are some similarities. However, some relations were found in the opposite direction expected.

Total number of network members and average frequency of interactions were positively correlated between the SIQ and FII. Perceptions of the overall relationship were related as measured by reciprocity, exploitation, and 
overprotectiveness on the SIQ and closeness, importance, and satisfaction on the FII. Several objective measures were found to correlate in the opposite direction expected. Specifically, as positive socializing, tangible and emotional interactions increased on the SIQ, negative expressive interactions increased on the FII. Examples of negative expressive interactions include doing something or providing information that causes worry or upset, giving unwanted advice, saying or doing something that discouraged the participant from getting better, and being unable to share feelings. In addition, as positive tangible support increased on the SIQ, negative instrumental interactions increased on the FII. As negative tangible interactions increased on the SIQ, positive expressive interactions increased on the FII. These findings become more of an enigma in light of the fact that, within the SIQ, positive and negative structural variables correlate in the expected direction (e.g., as negative variables increase, so do other negative variables). The unexpected findings may be related to the categories of social interactions measured. Cognitive guidance, socializing, tangible support, and emotional support as measured on the SIQ are not synonymous with instrumental and expressive interactions as measured on the FII. It is possible that the types of interactions correlated are too dissimilar to interpret or examine together.

Despite the fact that there is evidence that both the SIQ and FII measure similar aspects of social interactions, it is difficult to compare the SIQ with the FII because the only real structural measures of the SIQ include the total number of supports listed and the frequency of interactions, both of which correlate significantly in the expected direction with the same variables on the FII. The number of individuals associated with pleasant or unpleasant aspects of social interactions on the SIQ were calculated by selecting those individuals who were associated with at least "moderately" pleasant or upsetting interactions. In contrast, the FII asks for lists of people who are associated with positive and negative types of interactions without an indication of how positive or negative the interactions are. In addition, there are only three variables in the FII measuring one's perceptions. These include three questions about each network 
member in which the respondent is asked to rate, on a 4-point Likert scale, how close, how satisfied, and how important the person is to them. These questions are not mirrored per se in the SIQ. However, all three of these perceived FII measures were significantly positively associated with measures of exploitation and reciprocity on the SIQ. In addition, similar constructs in the FII and SIQ are phrased quite differently. For example, cognitive guidance is assessed on the FII by asking the participant to list individual "who has made helpful suggestions about how you might adjust your was of doing everyday activities?" and "who has given you unwanted advice about how you should change your ways of doing everyday activities?" In contract, the SIQ asks the respondent to rate on a 6point Likert scale how helpful and supportive and how upsetting or unsupporitve it to be "helped by this person in clearing up things that are confusing or providing information (e.g., legal or medical advice, who to call to have your lawn cut)". While the content measured is similar, the presentation may be different enough to result in significantly different responses. Since the SIQ and FII have similarities, but are not identical instruments, it is expected that they will not correlate in all areas. The fact that they are so strongly related on so many variables of perceived and structural interactions, provides evidence of concurrent validity.

The SIQ and FII were both found to be related to two measures of mental health (BDI and LSI). Since measures of social interactions are expected to be related to measures of mental health, it is important to note how the SIQ is related to measures of mental health. The FII is included in this discussion because the construct validity of the SIQ is being assessed in part, by its relation to the FII. It therefore seems necessary to address how well the FII relates to measures of mental health. The SIQ and FII are both related to the BDI and LSI, but the SIQ was more strongly correlated with the BDI and LSI than was the FII. One possible reason for the similar relation to the measures of mental health is that both the SIQ and FII measure the same construct (i.e., social interactions).

Temporal Stability. Retest scores were significantly correlated with initial scores, indicating that the SIQ is stable at least up to two weeks. It is interesting 
to note that in examining overall negative social interactions, negative socializing, negative tangible, negative emotional, exploitative, and reciprocal interactions, the 2-week retest data were more strongly correlated with initial scores on the SIQ than scores obtained at the 2-day retest. The opposite was true for measures of positive social interactions (i.e., correlation coefficients were stronger for 2-day vs. 2-week retest responses). The results reveal that participants tended to indicate that negative interactions were less negative 2 days later, but more similarly negative to initial administration 2-weeks later. These data suggest that perceptions of negative interactions fluctuate more than perceptions of positive interactions. This finding makes intuitive sense, since one negative event has been found to be more salient than several positive events (e.g., Cicirelli, 1990; Rook, 1984; Krause, 1995).

Internal consistency. Strong evidence was found for internal consistency. Results from the present study suggest that the SIQ is at least as reliable as other similar measures reported in the literature such as the FII (Stephens et al., 1987; Norris et al., 1990) and the ASSS (Revensen et al., 1991).

Limitations. This study is not without limitations. First, one might question the generalizability of the findings in light of the participant sample. For example, the sample included a group of primarily well educated, Caucasian women, in their early eighties, the majority of whom lived alone, and self-rated their health as better than average. The majority of participants also lived in senior communities and did not identify financial concerns as a stressor. Also, the investigator read or filled out some questionnaire forms for participants who complained of poor vision or shaky hands. Finally, the investigator called and scheduled meetings with some participants to prompt them to complete retest data whereas others were not prompted. The additional "social support" provided to some of the respondents may have impacted their perceptions of their own social interactions.

The high education level of the majority of participants may have misrepresented the ease with which the SIQ can be administered as a questionnaire. That is, a more representative sample population with less 
education may have had more difficulty completing the survey independently. The fact that most participants lived in some type of senior community, as opposed to individual houses, may have resulted in a sample that was more social and has more social opportunities than the average population.

The fact that some participants were read the questionnaires and others were not may have compromised the intended standardized presentation of the instruments, and may have confounded results in a variety of ways. Specifically, participants prone to suggestibility may have tried to respond in ways they believed the investigator wanted them to respond. The tone or facial expression of the investigator may have been leading to some participants. Also, participants may have been more likely to provide a response that they determined to be socially desirable since they responded to the investigator instead of indicating their own responses on the forms as the SIQ was intended. Socially desirable responses for some may have been to inflate the frequency of interactions to appear more popular, report that interactions were more positive than they actually perceived them to be in order to protect friends and family members, or even to report that interactions were more negative in order to obtain sympathy. Overall, the fact that some questionnaires were read to participants as opposed to being presented in a questionnaire format, as it was to others, may have impacted responses.

The fact the data points are dependent leads to a decrease in variability. That is, as discussed previously, the majority of participants involved in this study resided in the same city and several lived in the same senior community. As a result, participants were likely to have interacted with and reported on several of the same individuals in their responses to the SIQ. Such dependence in data points, due to sampling, reduces variability and may result in misleadingly lower correlations.

In relation to retest data, the results were examined in a between subject as opposed to a within subject format. This type of examination may have resulted in misleading findings. In addition, only twenty data points per time period were examined, providing questionable power in analyses. 
Finally, the fact that some participants were prompted to complete retest data with either a phone call or a visit means that some participants received additional social interactions (i.e., the interaction with the investigator) that others did not receive, possibly confounding results. That is, depending upon whether the participant found the interaction with the investigator pleasant or unpleasant when prompted to complete retest data may have impacted their mood and therefore their responses to the retest questions.

\section{Conclusion}

The present study offers evidence for the reliability and validity of the SIQ. The availability of this scale will permit others to measure positive and negative interactions more efficiently and thoroughly than existing measures have previously. The SIQ requires less time and effort to administer due to its questionnaire format and Likert-scales as opposed to the open-ended questions of other measures. The questionnaire format also reduces the concerns associated with social desirability confounds. That is, the questionnaire format decreases the likelihood that individuals will describe their social interactions in ways that will solicit sympathy, will make them appear more popular, or will make their friends or family appear more supportive. Finally, the SIQ incorporates all of the critical components of social interactions noted in the literature. An accurate and efficient measurement tool for social interactions in an older adult population could provide clinicians valuable insight into possible causes for decreased mental and physical health. If problematic social interactions can be easily identified, then they can be addressed as part of a comprehensive treatment plan.

\section{Future Research}

The present study found preliminary evidence supporting the psychometric properties of the SIQ. Further research is needed to provide additional normative data on the SIQ with other older adult pop ulations (e.g., nursing home residents, residents of assisted living facilities, residents of private homes or apartments vs. senior living communities, a higher representation of males). Additional evidence to support the construct validity of the SIQ is also needed. Since several 
participants in the present study requested that the SIQ be read to them, future research might include the administration of the SIQ in a standardized interview format to further explore the difference between questionnaire and interview presentation of the measure.

$\mathrm{BDI}$ and $\mathrm{LSI}$ results were significantly, negatively related $(r=-.472, p \leq .01)$. Since retest data did not re-examine mood with either measure, impact of current mood and relation between mood and the SIQ over time was not examined. Further examination of the impact of mood on perception of social interactions may shed light on the retest findings.

Since retest data in the present study suggested that perceptions of negative interactions are more labile than perceptions of positive interactions, administration of the SIQ over several time intervals may provide valuable data to further explore this finding.

Additional research could examine the scoring procedure utilized in the present study. Some "objective" measures were calculated by summing the number of network members associated with at least a "moderate" (as reported on a Likert-scale) level of pleasant or unpleasant interactions. Further evaluation of such a combination of perceived and structural components into one variable would be helpful for determining the utility of this type of variable, and whether other approaches to scoring the data available from the SIQ might be more appropriate. 


\section{References}

Abraham, I. L. (1992). Longitudinal reliability of the Life-Satisfaction Index (short form) with nursing home residents: A cautionary note. Perceptual Motor Skills, 75, 665-666.

Adams, D. L. (1969). Analysis of Life Satisfaction Index. Journal of Gerontology, 24, 470-474.

Andrews, F. M., \& Withey, S. B. (1976). Social indicators of well-being: American's perceptions of life quality. New York, NY: Plenum Press.

Antonucci, T. C., \& Akiyama, H. (1987). Social networks in adult life and a preliminary examination of the Convoy Model. Journal of Gerontology, 42, 519527.

Avioli, P. S. (1989). The social support functions of siblings in later life. American Behavioral Scientist, 33, 45-57.

Baltes, M. M., \& Silverberg, S. B. (1994). The dynamics between dependency and autonomy: Illustrations across the life span. In D. L. Featherman, R. M. Lerner, \& M. Perlmutter (Eds.), Life-Span Development and Behavior (Vol. 12, pp. 41-90). Hillsdale, NJ: Lawrence Erlbaum Associates.

Barrera, M., Jr., Sandler, I. N., \& Ramsay, T. B. (1981). Preliminary development of a scale of social support: Studies on college students. American Journal of Community Psychology, 9, 435-447.

Beck, A. T., Ward, C. H., Mendelson, M., Mock, J., \& Erbaugh, J. (1961). An inventory for measuring depression. Archives of General Psychiatry, 4, 561571.

Bolger, N., \& Eckenrode, J. (1991). Social relationships, personality, and anxiety during a major stressful event. Journal of Personality and Social Psychology, 3, 440-449.

Bornstein, R. F. (1995). Interpersonal dependency and physical illness: The mediating roles of stress and social support. Journal of Social and Clinical Psychology, 14, 225-243. 
Burckhardt, C. S., Woods, S. L., Schultz, A. A., \& Ziebarth, D. M. (1989). Quality of life of adults with chronic illness: A psychometric study. Research in Nursing Health, 12, 347-354.

Carstensen, L. L. (1992). Social and emotional patterns in adulthood: Support for socioemotional selectivity theory. Psychology and Aging, 7, 331-338.

Carstensen, L. L., \& Turk-Charles, S. (1994). The salience of emotion across the adult life-span. Psychology and Aging, 9, 259-264.

Cicirelli, V. G. (1990). Family support in relation to health problems of the elderly. In T. H. Brubaker (Ed.), Family Relationships in Later Life (pp. 212-228). Newbury Park, CA: Sage.

Cohen, S., Sherrod, D. R., \& Clark, M. S. (1986). Social skills and the stress-protective role of social support. Journal of Personality and Social Psychology, 50, 963-973.

Coyne, J. C., Wortman, C. B., \& Lehman, D. R. (1988). The other side of support: Emotional overinvolvement and miscarried helping. In B. H. Gottlieb (Ed.), Marshaling Social Support: Formats, Processes, and Effects (pp. 305330). Newbury Park, CA: Sage.

Cresswell, C. M., Kuipers, L., \& Power, M. J. (1992). Social networks and support in long-term psychiatric patients. Psychological Medicine, 22, 10191026.

Cutrona, C. E., Cohen, B. B., \& Igram, S. (1990). Contextual determinants of the perceived supportiveness of helping behaviors. Journal of Social and Personal Relationships, 7, 553-562.

Dean, A., Kolody, B., \& Wood, P. (1990). Effects of social-support from various sources on depression in elderly persons. Journal of Health and Social Behavior, 31, 148-161.

Endicott, J., \& Spitzer, R. L. A. (1978). A diagnostic interview: The schedule for affective disorders and schizophrenia. Archives of General Psychiatry, 35, 837-844.

Finch, J. F. \& Zautra, A. J. (1992). Testing latent longitudinal models of social ties and depression among the elderly: A comparison of distribution-free 
and maximum likelihood estimates with nonnormal data. Psychology and Aging, 7, 107-118.

Finch, J. F., Okun, M. A., Barrera, M., Zautra, A. J., \& Reich, J. W. (1980). Positive and negative social ties among older adults: Measurement models and the prediction of psychological distress and well-being. American Journal of Community Psychology, 17, 585-605.

Fiore, J. Becker, J., \& Coppel, D. B. (1983). Social network interactions: A buffer or a stress. American Journal of Community Psychology, 11, 423-439.

Fischer, C. S. (1982). To dwell among friends: Personal networks in town and city. Chicago: University of Chicago Press.

Fischer, J., \& Corcoran, K. (1994). Measures of clinical practice: A sourcebook Vol., Adults. New York, NY: The Free Press.

Friedman, M. M., \& King, K. B. (1994). The relationship of emotional and tangible support to psychological well-being among older women with heart failure. Research in Nursing and Health, 17, 433-440.

Gallagher, D. (1986). Assessment of depression by interview methods and psychiatric rating scales. In L. W. Poon (Ed.), Handbook for Clinical Memory Assessment in Older Adults, (pp. 202-225). Washington, DC: American Psychological Association.

Gallagher, D. Thompson, L. W., \& Levy, S. M. (1980). Clinical psychology assessment of older adults. In L. W. Poon (Ed.), Aging in the 1980's. Washington, DC: American Psychological Association.

Gallagher-Thompson, D., Nies, G., \& Thompson, L. W., (1982). Reliability of the Beck Depression Inventory with older adults. Journal of Consulting and Clinical Psychology, 50, 152-153.

Gurland, B. J., Kuriansky, J., Sharpe, L., Simon, R., Stiller, P., \& Birkett, P. (1977). The comprehensive assessment and referral evaluation (CARE):

Rationale, development and reliability. International Journal of Aging and Human Development, 8, 80-92.

Hansson, R. O., \& Carpenter, B. N. (1994). Relationships in old age: Coping with the challenge of transition (S. Duck, Ed.). New York, NY: Guilford. 
Helgeson, V. S. (1993). Two important distinctions in social support: Kind of support and perceived versus received. Journal of Applied Social Psychology, $\underline{23}, 825-845$.

Hirsch, B. J. (1980). Natural support systems and coping with major life changes. American Journal of Community Psychology, 8, 159-172.

Ingersoll-Dayton, B, Morgan, D., \& Antonucci, T. (1997). The effects of positive and negative social exchanges on aging adults. Journals of Gerontology, 52B, S190-S199.

Jennison, K. M. (1992). The impact of stressful life events and social support on drinking among older adults: A general population survey. International Journal of Aging and Human Development, 35, 99-123.

Jung, J. (1990). The role of reciprocity in social support. Basic and Applied Social Psychology, 11, 243-253.

Kalish, K.D. \& Edelstein, B.A. (1996) Buffering effects of coping on depression associated with negative social interactions in older adults. Unpublished.

Kaniasty, K., \& Norris, F. H. (1992). Social support and victims of crime: Matching event, support, and outcome. American Journal of Community Psychology, 20, 211-241.

Kaplan, R. M., \& Toshima, M. T. (1990). The functional effects of social relationships on chronic illness and disability. In B. R. Sarason, I. G. Sarason, \& G. Roiphe. Pierce (Eds.), Social support: An interactional view (pp. 427-453). New York: Wiley.

Kendall, C. Hollon, S. D., Beck, A. T., Hammen, C. L., \& Ingram, R. E. (1987). Issues and recommendations regarding use of the Beck Depression Inventory. Cognitive Therapy and Research, 11, 289-299.

Kiecolt-Glaser, J. K., Dyer, C. S., \& Shuttleworth, E. C. (1988). Upsetting social interactions and distress among Alzheimer's disease family care-givers: A replication and extension. American Journal of Community Psychology, 16, 825837. 
Kozma, A., \& Stones, M. J. (1988). Social desirability in measures of subjective well-being: Age comparisons. Social Indications Research, 20, 1-14.

Krause, N. (1986). Social support, stress, and well-being among older adults. Journal of Gerontology, 41, 512-519.

Krause, N. (1987). Chronic financial strain, social support, and depressive symptoms among older adults. Psychology and Aging, 2, 185-192.

Krause, N. (1990). Perceived health problems, formal/informal support, and life satisfaction among older adults. Journals of Gerontology, Social Sciences, 45, S193-S205.

Krause, N. (1995). Negative interaction and satisfaction with social support among older adults. Journals of Gerontology: Psychological Sciences, 50, P59-P73.

Lang, F., \& Carstensen, L. L. (1994). Close emotional relationships in late life: Further support for proactive aging in the social domain. Psychology and Aging, 9, 315-324.

Langer, E. J., \& Rodin, J. (1976). The effects of choice and enhanced personal responsibility for the aged: A field experiment in an institutional setting. Journal of Personality and Social Psychology, 34, 191-198.

Levy, S. M., Herberman, R. B., Whiteside, T., Sanzo, K., Lee, J., \& Kirkwood, J. (1990). Perceived social support and tumor estrogen/progesterone receptor status as predictors of natural killer cell activity in breast cancer patients. Psychosomatic Medicine, 52, 73-85.

Martin, R., Davis, G. M., Baron, R. S., Suls, J., \& Blanchard, E. B. (1994). Specificity in social support: Perceptions of helpful and unhelpful provider behaviors among irritable bowel syndrome, headache, and cancer patients. Health Psychology, 13, 432-439.

Morgan, D. L. (1989). Adjusting to widowhood: Do social networks really make it easier? The Gerontologist, 29, 101-107.

Morgan, D. L., Neal, M. B., \& Carder, P. C. (1997). Both what and when: The effects of positive and negative aspects of relationships on depression 
during the first 3 years of widowhood. Journal of Clinical Geropsychology, 3, 7391.

Neugarten, B., Havinghurst, R. Tobin, S. (1961). The measurement of life satisfaction. Journal of Gerontology, 16, 134-143.

Norris, V. K., Stephens, M. A. P., Kinney, J. M. (1990). The impact of family interaction on recovery from stroke: Help or hindrance? The Gerontologist, $\underline{4}, 535-542$.

Okun, M., Melichar, J. F., \& Hill, M. D. (1990). Negative daily events, positive and negative social ties, and psychological distress among older adults. The Gerontologist, 2, 193-199.

Pachana, N. A., Gallagher-Thompson, D., \& Thompson, L. W. (1994). Assessment of depression. In M. P. Lawton \& J. A. Teresi (Vol. Eds.), Annual review of gerontology and geriatrics: Vol. 14. Focus on assessment techniques (pp. 234-256). New York, NY: Springer Publishing.

Pagel, M. D., Erdly, W. W., \& Becker, J. (1987). Social networks: We get by with (and in spite of) a little help from our friends. Journal of Personality and Social Psychology, 53, 793-804.

Parker, G. Tupling, H., \& Brown, L. B. (1979). A parental bonding instrument. British Journal of Medical Psychology, 44, 127-139.

Potts, M. K., Hurwicz, M., Goldstein, M. S., \& Berkanovic, E. (1992). Social support, health-promotive beliefs, and preventive health behaviors among the elderly. Journal of Applied Gerontology, 11, 425-440.

Radloff, L. S. (1977). The CES-D scale: A self-report depression scale for research in the general population. Applied Psychological Measurement, 3, 385401.

Rauktis, M. E., Koeske, G. F., \& Tereshko, O. (1995). Negative social interactions, distress, and depression among those caring for a seriously and persistently mentally ill relative. American Journal of Community Psychology, 23, 279-299. 
Revensen, T. A., \& Schiaffino, K. M. (1990, October). Development of a contextual social support measure for use with arthritis populations. Paper presented at the a

Revenson, T. A., Schiaffino, K. M., Majerovitz, D., \& Gibofsky, A. (1991). Social support as a double-edged sword: The relation of positive and problematic support to depression among rheumatoid arthritis patients. Social Science Medicine, 33, 807-813.

Revicki, D. A., \& Mitchell, J. P. (1990). Strain, social support, and mental health in rural elderly individuals. Journal of Gerontology: Social Sciences, 45 , S267-274.

Reynolds, W., Remer, R., \& Johnson, M. (1995). Marital satisfaction in later life: An examination of equity, equality, and reward theories. International Journal of Aging and Human Development, 40, 155-173.

Rivera, P. A., Rose, J. M., Futterman, A., Lovett, S. B., GallagherThompson, D. (1991). Dimensions of perceived social support in clinically depressed and non-depressed female caregivers. Psychology and Aging, 6, 232237.

Roberto, K. A., \& Scott, J. P. (1986). Equity considerations in the friendships of older adults. Journal of Gerontology, 2, 241-247.

Rodin, J., \& Langer, E. J. (1977). Long-term effects of a control-relevant intervention with the institutionalized aged. Journal of Personality and Social Psychology, 35, 897-902.

Rook, K. S. (1984). The negative side of social interaction: Impact on psychological well-being. Journal of Personality and Social Psychology, 5, 10971108.

Rook, K. S. (1987). Reciprocity of social exchange and social satisfaction among older women. Journal of Personality and Social Psychology, 52, 145-154.

Rook, K. S. (1990). Stressful aspects of older adults' social relationships: Current theory and research. In M. A. P. Stephens, J. H. Crowther, S. E. Hobfoll, \& D. L. Tennenbaum (Eds.), Stress and coping in later-life families (pp. 173192). New York, NY: Hemisphere. 
Rook, K. S. (1994). Assessing the health-related dimensions of older adults' social relationships. In M. P. Lawton \& J. A. Teresi (Eds.), Annual review of gerontology and geriatrics: Focus on assessment techniques (Vol. 14, pp. 142-181). New York, NY: Springer.

Rook, K. S. (1997). Positive and negative social exchanges: Weighing their effects in later life. Journals of Gerontology, 52B, S167-S169.

Rook, K. S., \& Dooley, D. (1985). Applying social support research: Theoretical and future directions. Journal of Social Issues, 41, 5-28.

Rotenberg, K. J., \& Hamel, J. (1988). Social interaction and depression in elderly individuals. International Journal of Aging and Human Development, 27, 305-318.

Russell, D. W., \& Cutrona, C. E. (1991). Social support, stress, and depressive symptoms among the elderly: Test of a process model. Psychology and Aging, 6, 190-201.

Salamon, M. J. (1988). Clinical use of the Life Satisfaction in the Elderly Scale. Clinical Gerontologist, 8, 45-54.

Schaefer C., Coyne, J. C., \& Lazarus, R. S. (1981). The health-related functions of social support. Journal of Behavioral Medicine, 4, 381-406.

Schuster, T. L., Kessler, R. C., \& Aseltine, R. H. (1990). Supportive interactions, negative interactions, and depressed mood. American Journal of Community Psychology, 18, 423-438.

Shinn, M., Lehmann, S., Wong, N. W. (1984). Social interaction and social support. Journal of Social Issues, 40, 55-76.

Spitzer, R. L., Endicott, J. P., \& Robbins, E. (1978). Research diagnostic criteria. Archives of General Psychiatry, 35, 773-786.

Steinbach, U. (1992). Social networks, instituationalization, and mortality among elderly people in the United States. Journals of Gerontology: Social Sciences, 47, S183-S190.

Stephens, M. A. P., Kinney, J. M., Norris, V. K., Ritchie, S. W. (1987). Social networks as assets and liabilities in recovery from stroke by geriatric patients. Psychology and Aging, 2, 125-129. 
Talbott, M. M. (1990). The negative side of the relationship between older widows and their adult children: The mother's perspective. The Gerontologist, 30, 595-603.

Thompson, S. C., \& Sobolew-Shubin, A. (1993a). Perceptions of overprotection in ill adults. Journal of Applied Social Psychology, 23, 85-97.

Thompson, S. C., \& Sobolew-Shubin, A. (1993b). Overprotective relationships: A nonsupportive side of social networks. Basic and Applied Social Psychology, 14, 363-383.

Thompson, S. C., Sobolew-Shubin, A., Graham, M. A., \& Graham, M. A., \& Janigian, A. S. (1989). Psychosocial adjustment following a stroke. Social Science and Medicine, 28, 239-247.

Walker, K. N., McBride, A., Vachon, M. L. S. (1977). Social support networks and the crisis of bereavement. Social Science and Medicine, 11, 35-41.

Wilson, J. G., Calsyn, R. J., \& Orlofsky, J. L. (1994). Impact of sibling relationships on social support and morale in the elderly. Journal of Gerontological Social Work, 22, 157-170.

Wolchik, S., Sandler, I., \& Braver, S. (1987). Social support: Its assessment and relation to children's adjustment. In N. Eisenberg (Ed.), Contemporary topics in develepmental psychology (pp.319-349). New York: Wiley.

Wolfe, R., Morrow, J., Fredrickson, B.L. (1996). Mood disorders in older adults. In L. Carstensen, B.A. Edelstein, \& L. Dornbrand (Eds.), The practical handbook of clinical gerontology (pp. 274-303). California: Sage.

Wood, V., Wylie, M. L., \& Sheafor, B. (1969). An analysis of a short selfreport measure of life satisfaction: Correlation with rater judgments. Journal of Gerontology, 24, 465-469.

Yesavage, J. A., Brink, T. L., \& Rose, T. L. (1983). Development and validation of a geriatric depression scale. Journal of Psychiatric Residents, 17, 37-49. 
Table 1

Examples of Findings from Studies Examining Specificity of Need

\begin{tabular}{|c|c|c|}
\hline Stressor & $\begin{array}{l}\text { Illustrative } \\
\text { study }\end{array}$ & Findings \\
\hline Stroke & $\begin{array}{l}\text { Norris et al. } \\
(1990)\end{array}$ & $\begin{array}{l}\text { Problematic instrumental and tangible interactions were linked } \\
\text { to decreased independence in ADLs. Problematic expressive } \\
\text { interactions were linked to decreased well-being and physical } \\
\text { health. }\end{array}$ \\
\hline $\begin{array}{l}\text { Crime and } \\
\text { Legal Issues }\end{array}$ & Krause (1986) & $\begin{array}{l}\text { Emotional support buffered the effects of crime on well-being. } \\
\text { Informational and tangible support was not related to well- } \\
\text { being. }\end{array}$ \\
\hline \multirow[t]{2}{*}{ Bereavement } & Krause (1986) & $\begin{array}{l}\text { Informational, tangible, and emotional support buffered the } \\
\text { effects of bereavement on well-being. }\end{array}$ \\
\hline & $\begin{array}{l}\text { Walker, } \\
\text { MacBride, \& } \\
\text { Vachon (1977) }\end{array}$ & $\begin{array}{l}\text { Emotional support was more beneficial immediately after } \\
\text { bereavement, tangible support was more helpful months later, } \\
\text { and informational support was not linked to helpfulness. }\end{array}$ \\
\hline $\begin{array}{l}\text { Financial } \\
\text { Strain }\end{array}$ & Krause (1987) & $\begin{array}{l}\text { Informational support buffered the effects of financial strain on } \\
\text { depressive symptoms and emotional and tangible support had } \\
\text { no effect on depressive symptoms. }\end{array}$ \\
\hline $\begin{array}{l}\text { Cancer vs. } \\
\text { non- } \\
\text { catastrophic } \\
\text { chronic illness }\end{array}$ & $\begin{array}{l}\text { Martin, Davis, } \\
\text { Baron, Suls, \& } \\
\text { Blanchard } \\
\text { (1994) }\end{array}$ & $\begin{array}{l}\text { Cancer patients found emotional support most helpful, chronic } \\
\text { illness patients found tangible support most helpful, and } \\
\text { informational support was not identified as helpful for either } \\
\text { group. }\end{array}$ \\
\hline Heart Failure & $\begin{array}{l}\text { Friedman \& } \\
\text { King (1994) }\end{array}$ & $\begin{array}{l}\text { Emotional support was directly related to increased positive } \\
\text { affect and life satisfaction, tangible support was related to } \\
\text { decreased negative affect. Neither emotional nor tangible } \\
\text { support produced buffering effects. }\end{array}$ \\
\hline $\begin{array}{l}\text { Upsetting } \\
\text { scenario }\end{array}$ & $\begin{array}{l}\text { Cutrona, } \\
\text { Cohen, Igram } \\
(1990)\end{array}$ & $\begin{array}{l}\text { Emotional support was viewed as helpful and supportive and } \\
\text { instrumental support was not. }\end{array}$ \\
\hline $\begin{array}{l}\text { Caregiving for } \\
\text { AD spouses }\end{array}$ & $\begin{array}{l}\text { Fiore, Becker, } \\
\text { \& Coppel } \\
(1983)\end{array}$ & $\begin{array}{l}\text { Problems with cognitive support accounted for more variance } \\
\text { in depression scores than problems with socializing, tangible } \\
\text { assistance, emotional support, and self-disclosure. }\end{array}$ \\
\hline
\end{tabular}


Table 2

Measures of Social Interactions

\begin{tabular}{|c|c|c|c|c|}
\hline Measure & $\begin{array}{l}\text { Reviewed } \\
\text { studies } \\
\text { utilizing this } \\
\text { instrument }\end{array}$ & $\begin{array}{l}\text { Dimension of } \\
\text { NSIs measured }\end{array}$ & Description & $\begin{array}{c}\text { Reliability and } \\
\text { Validity }\end{array}$ \\
\hline $\begin{array}{c}\text { Social } \\
\text { Network } \\
\text { Interview } \\
\text { (SNI) }\end{array}$ & $\begin{array}{l}\text { - Fiore et al. } \\
\text { (1983) } \\
\text { - Pagel et al. } \\
\text { (1987) } \\
\text { - Kiecolt- } \\
\text { Glaser et } \\
\text { al. (1988) }\end{array}$ & $\begin{array}{l}\text { - socializing } \\
\text { - tangible } \\
\text { assistance } \\
\text { - cognitive } \\
\text { guidance } \\
\text { - emotional } \\
\text { support } \\
\text { - self-disclosure }\end{array}$ & $\begin{array}{l}10 \text { closest network members are } \\
\text { identified and rated on how helpful } \\
\text { and upsetting they are in five } \\
\text { dimensions of perceived support. } \\
\text { Two scores (helpful and upsetting) } \\
\text { are obtained for each dimension of } \\
\text { SIs for each subject. Interview } \\
\text { format. }\end{array}$ & $\begin{array}{l}\text { No Reliability Data. } \\
\text { Correlated with a } \\
\text { depression measure } \\
\text { in the expected } \\
\text { direction. }\end{array}$ \\
\hline $\begin{array}{c}\text { Negative } \\
\text { Social Ties } \\
(\mathrm{NST})\end{array}$ & $\begin{array}{l}\bullet \text { Finch et al. } \\
(1989) \\
- \text { Finch \& } \\
\text { Zautra } \\
(1992)\end{array}$ & $\begin{array}{l}\text { - criticizing } \\
\text { - breaking } \\
\text { promises } \\
\text { - taking } \\
\text { advantage } \\
\text { - provoking } \\
\text { anger } \\
\end{array}$ & $\begin{array}{c}\text { A 14-item objective social } \\
\text { interaction scale with } 4 \text { items } \\
\text { assessing the number of NSI } \\
\text { providers and } 10 \text { items assessing } \\
\text { the number of instrumental PSIs } \\
\text { over the past } 6 \text { months. Interview } \\
\text { format. }\end{array}$ & $\begin{array}{l}\text { Internal consistency } \\
\text { (Cronbachs alpha) }= \\
\text { 79. Correlated with } \\
\text { an emotional health } \\
\text { measure in the } \\
\text { expected direction. }\end{array}$ \\
\hline $\begin{array}{l}\text { Problematic } \\
\text { Social Ties } \\
\quad \& \\
\text { Exchanges } \\
\text { (PST) }\end{array}$ & •Rook (1984) & $\begin{array}{l}\text { - socializing } \\
\bullet \text { emotional } \\
\text { support } \\
\text { • instrumental } \\
\text { support }\end{array}$ & $\begin{array}{l}5 \text { questions identify sources of SIs, } \\
\text { measure is objective (\# of persons } \\
\& \text { frequency of contacts in each of } \\
\text { five areas). } \\
\text { Interview format. }\end{array}$ & $\begin{array}{l}\text { No internal } \\
\text { consistency data. } \\
\text { Correlated with an } \\
\text { emotional health } \\
\text { measure in the } \\
\text { expected direction. }\end{array}$ \\
\hline $\begin{array}{l}\text { Frequency } \\
\quad \text { of } \\
\text { Interactions } \\
\text { Inventory } \\
\text { (FII) }\end{array}$ & $\begin{array}{l}\text { •Stephens et } \\
\text { al. (1987) } \\
\text { • Norris et al. } \\
\text { (1990) }\end{array}$ & $\begin{array}{l}\text { - undependable } \\
\text { - upsetting } \\
\text { • bad advice or } \\
\text { information } \\
\text { - discouraging } \\
\text { - overprotection } \\
\text { - does not share } \\
\text { feelings } \\
\text { - made you } \\
\text { self conscious }\end{array}$ & $\begin{array}{l}\text { Network members providing SIs in } \\
\text { the past } 2 \text { months are identified. } \\
\text { Frequency of interactions, } \\
\text { closeness, and importance of } \\
\text { network person to the respondent is } \\
\text { assessed. Structural and perceived } \\
\text { information is obtained. } \\
\text { Interview format. }\end{array}$ & $\begin{array}{c}\text { Test-retest } \\
\text { correlation } \\
\text { coefficient=.77 at } \\
\text { one week. Internal } \\
\text { consistency } \\
\text { (Cronbachs alpha) }= \\
.67 . \\
\text { Correlated with a } \\
\text { measure of morale } \\
\text { and psychiatric } \\
\text { symptoms in the } \\
\text { expected direction. }\end{array}$ \\
\hline
\end{tabular}

(table continues) 
Table 2

\section{Measures of Social Interactions-continued}

\begin{tabular}{|c|c|c|c|c|}
\hline Measure & $\begin{array}{c}\text { Reviewed } \\
\text { studies } \\
\text { utilizing this } \\
\text { instrument }\end{array}$ & $\begin{array}{l}\text { Dimension of } \\
\text { NSIs measured }\end{array}$ & Description & $\begin{array}{c}\text { Reliability and } \\
\text { Validity }\end{array}$ \\
\hline $\begin{array}{l}\text { Social } \\
\text { Support } \\
\text { Structural } \\
\text { Interview } \\
\text { (SSSI) }\end{array}$ & $\begin{array}{l}\text { • Okun et al. } \\
(1990)\end{array}$ & $\begin{array}{l}\text { - emotional } \\
\text { support } \\
\text { - tangible aid } \\
\text { - cognitive } \\
\text { guidance } \\
\text { - self- } \\
\text { disclosure } \\
\text { - socializing } \\
\end{array}$ & $\begin{array}{l}\text { Network members are identified } \\
\text { and rated on how helpful and } \\
\text { upsetting they are in each } \\
\text { dimension. Subjective measure. } \\
\text { Interview format. }\end{array}$ & $\begin{array}{l}\text { No reliability data. } \\
\text { Correlated with a } \\
\text { measure of } \\
\text { emotional health in } \\
\text { the expected } \\
\text { direction. }\end{array}$ \\
\hline $\begin{array}{l}\text { Over- } \\
\text { protection } \\
\text { Scale for } \\
\text { Adults } \\
\text { (OPSA) }\end{array}$ & $\begin{array}{l}- \text { Thompson } \\
\text { \& Sobolew- } \\
\text { Shubin } \\
(1993 \mathrm{a}, \\
1993 \mathrm{~b})\end{array}$ & - overprotection & $\begin{array}{l}\text { Subjects rate their caregivers with } \\
\text { an } 18 \text {-item instrument on how } \\
\text { overprotective they are on a } 4- \\
\text { point scale of subjective degree of } \\
\text { overprotection. Questionnaire } \\
\text { format. }\end{array}$ & $\begin{array}{c}\text { Internal consistency } \\
(\text { Cronbachs alpha })= \\
.88 . \\
\text { Correlated with the } \\
\text { Parental Bonding } \\
\text { Instrument }(\mathrm{r}=.63, \mathrm{p} \\
<.001) .\end{array}$ \\
\hline $\begin{array}{l}\text { Aspects of } \\
\text { Personal } \\
\text { Networks } \\
\text { (ASPN) }\end{array}$ & $\begin{array}{l}\text { - Morgan et } \\
\text { al. (1997) }\end{array}$ & $\begin{array}{l}\text { • informational } \\
\text { support } \\
\text { • emotional } \\
\text { support } \\
\text { • instrumental } \\
\text { support } \\
\end{array}$ & $\begin{array}{c}\text { Up to } 30 \text { network members are } \\
\text { identified, the number of people } \\
\text { providing SIs are obtained for each } \\
\text { dimension of SI, resulting in only } \\
\text { objective measures. } \\
\text { Interview format. }\end{array}$ & $\begin{array}{c}\text { No reliability or } \\
\text { validity data. }\end{array}$ \\
\hline $\begin{array}{l}\text { Arizona } \\
\text { Social } \\
\text { Support } \\
\text { Interview } \\
\text { Schedule } \\
\text { (ASSIS) }\end{array}$ & $\begin{array}{l}\text { - Rivera et al. } \\
\text { (1991) }\end{array}$ & $\begin{array}{l}\text { - material aid } \\
\text { - physical } \\
\text { assistance } \\
\text {-intimate } \\
\text { interactions } \\
\text { - guidance } \\
\text { - feedback }\end{array}$ & $\begin{array}{l}\text { Potential sources of support are } \\
\text { listed for each dimension, then they } \\
\text { are each rated on how much } \\
\text { support is received and how } \\
\text { satisfied they are with the support, } \\
\text { resulting in both objective and } \\
\text { subjective scores. Interview } \\
\text { format. }\end{array}$ & $\begin{array}{l}\text { While substantial } \\
\text { psychometric } \\
\text { information is } \\
\text { available on the } \\
\text { original instrument, } \\
\text { no such data are } \\
\text { available for the } \\
\text { instrument revised } \\
\text { by Rivera et } \\
\text { al.(1991). } \\
\text { The original } \\
\text { instrument did not } \\
\text { examine NSIs. }\end{array}$ \\
\hline
\end{tabular}

Note. $\mathrm{SI}=$ Social Interaction, NSI=Negative Social Interaction 


\section{Table 3}

\section{Frequency Table of Demographic Variables}

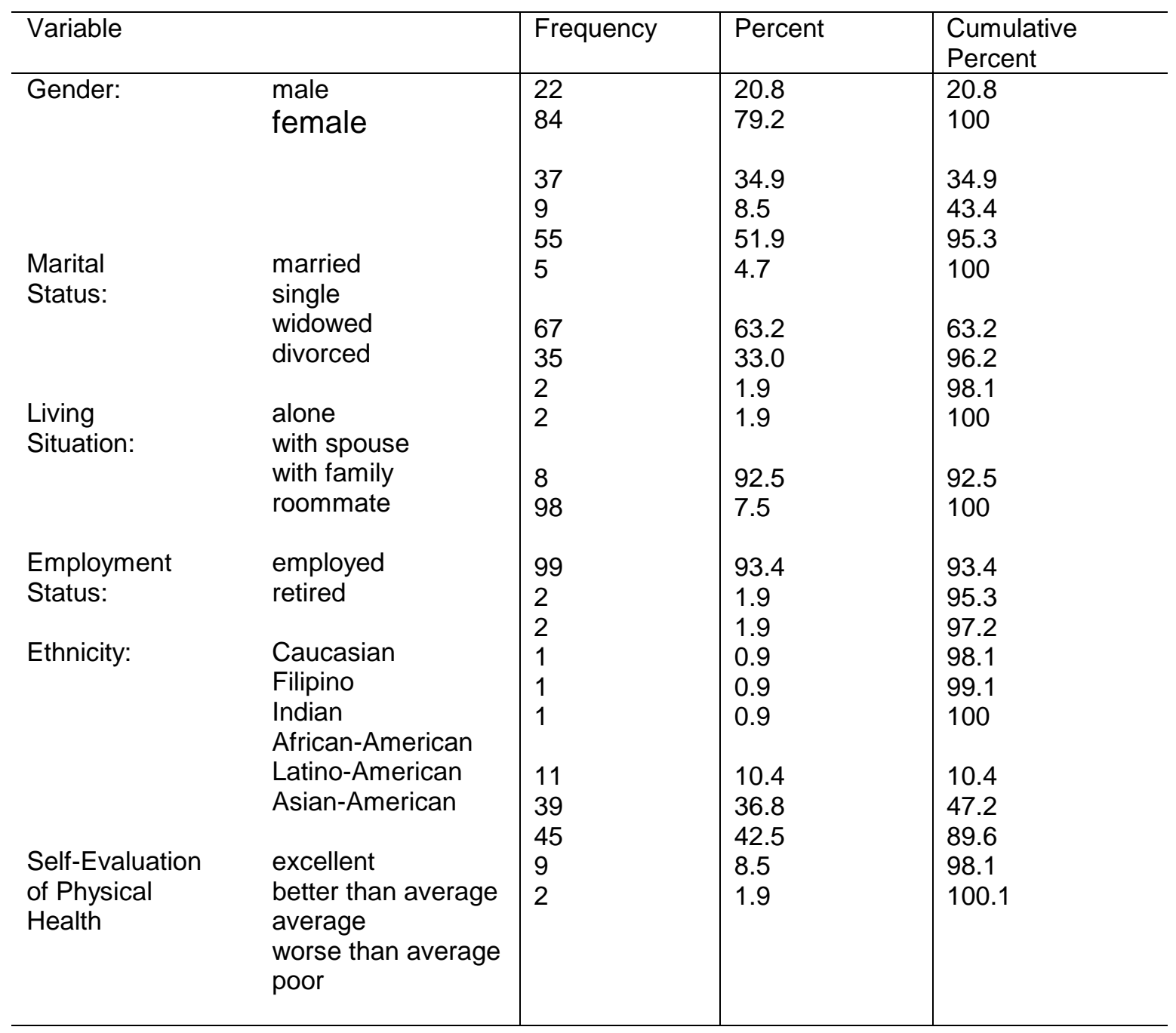


Table 4

Descriptive Statistics:

Means of Demographic Variables by Endorsement of Stressors

\begin{tabular}{|c|c|c|c|c|c|c|c|}
\hline Stressor & Age & Gender & $\begin{array}{l}\text { Marital } \\
\text { Status }\end{array}$ & $\begin{array}{l}\text { Living } \\
\text { Situation }\end{array}$ & $\begin{array}{l}\text { physical } \\
\text { health }\end{array}$ & Ethnicity & Education \\
\hline retired & 72 & equal & married & $\begin{array}{l}\text { with } \\
\text { spouse }\end{array}$ & $\begin{array}{l}\text { better } \\
\text { than } \\
\text { average }\end{array}$ & Caucasian & 15.3 \\
\hline $\begin{array}{l}\text { moved to } \\
\text { new home }\end{array}$ & 84.2 & women & widowed & alone & $\begin{array}{l}\text { better } \\
\text { than } \\
\text { average }\end{array}$ & Caucasian & 13.4 \\
\hline $\begin{array}{l}\text { illness of } \\
\text { participant }\end{array}$ & 82.3 & women & widowed & alone & average & Caucasian & 14.5 \\
\hline $\begin{array}{l}\text { illness of } \\
\text { spouse }\end{array}$ & 81.7 & women & married & $\begin{array}{l}\text { with } \\
\text { spouse }\end{array}$ & average & Caucasian & 15 \\
\hline $\begin{array}{l}\text { financial } \\
\text { concerns }\end{array}$ & 77.5 & women & divorced & alone & average & Caucasian & 13.8 \\
\hline $\begin{array}{l}\text { caretaker } \\
\text { of other }\end{array}$ & 78 & women & widowed & alone & average & Caucasian & 14.3 \\
\hline $\begin{array}{l}\text { death of } \\
\text { other }\end{array}$ & 80.7 & women & widowed & alone & average & Caucasian & 14.9 \\
\hline full sample & 80.8 & women & widowed & alone & average & Caucasian & 14.4 \\
\hline
\end{tabular}


Table 5

Descriptive Statistics

\begin{tabular}{|c|c|c|c|c|}
\hline Variable & Minimum & Maximum & Mean & $\begin{array}{l}\text { Standard } \\
\text { Deviation }\end{array}$ \\
\hline Age & 61 & 96 & 80.80 & 8.34 \\
\hline Education & 7.00 & 21.00 & 14.40 & 2.63 \\
\hline $\mathrm{BDI}$ & .00 & 26.00 & 8.66 & 5.02 \\
\hline LSI & 2.00 & 26.00 & 18.33 & 4.49 \\
\hline SIQ:\# network members & 1.00 & 10.00 & 7.08 & 2.34 \\
\hline SIQ:\# pos. network members & .00 & 10.00 & 4.63 & 2.61 \\
\hline SIQ:\# neg network members & .00 & 1.00 & .01 & .23 \\
\hline SIQ:mean pos & 2.36 & 5.78 & 4.25 & .67 \\
\hline SIQ:mean neg & 1.00 & 4.33 & 1.52 & .46 \\
\hline SIQ:soc-pos-mean & 2.67 & 6.00 & 5.33 & .63 \\
\hline SIQ:soc-neg-mean & 1.00 & 6.00 & 2.39 & 1.01 \\
\hline SIQ:soc-pos-tot & 1.00 & 10.00 & 6.46 & 2.37 \\
\hline SIQ:soc-neg-tot & .00 & 6.00 & 1.75 & 1.61 \\
\hline SIQ:tan-pos-mean & 1.00 & 6.00 & 2.79 & 1.21 \\
\hline SIQ:tan-neg-mean & 1.00 & 6.00 & 1.24 & .58 \\
\hline SIQ:tan-pos-tot & .00 & 10.00 & 2.77 & 2.36 \\
\hline SIQ:tan-neg-tot & .00 & 3.00 & .21 & .51 \\
\hline SIQ:cog-pos-mean & 1.00 & 6.00 & 3.14 & 1.23 \\
\hline SIQ:cog-neg-mean & 1.00 & 3.00 & 1.38 & .52 \\
\hline SIQ:cog-pos-tot & .00 & 9.00 & 3.20 & 2.30 \\
\hline SIQ:cog-neg-tot & .00 & 3.00 & .44 & .72 \\
\hline SIQ:emot-pos-mean & 1.83 & 6.00 & 4.94 & .84 \\
\hline SIQ:emot-neg-mean & 1.00 & 6.00 & 1.41 & .74 \\
\hline SIQ:emot-pos-tot & 1.00 & 10.00 & 5.94 & 2.38 \\
\hline SIQ:emot-neg-tot & .00 & 4.00 & .44 & .86 \\
\hline SIQ:exploitative mean & 1.00 & 6.00 & 1.31 & .63 \\
\hline SIQ:exploitative-yes-tot & .00 & 4.00 & .31 & .70 \\
\hline SIQ:exploitative-no-tot & .00 & 10.00 & 6.76 & 2.36 \\
\hline SIQ:overprotective-mean & 1.00 & 3.14 & 1.40 & .50 \\
\hline SIQ:overprotective-yes-tot & .00 & 4.00 & .34 & .72 \\
\hline SIQ:overprotective-no-tot & 1.00 & 10.00 & 6.74 & 2.35 \\
\hline SIQ:reciprocal-mean & 1.00 & 6.00 & 5.05 & .89 \\
\hline SIQ:reciprocal-yes-tot & .00 & 10.00 & 6.03 & 2.34 \\
\hline SIQ:reciprocal-no-tot & .00 & 10.00 & 1.05 & 1.46 \\
\hline FII:\# network members & .00 & 12.00 & 5.31 & 2.93 \\
\hline FII:\# pos network members & .00 & 12.00 & 6.63 & 4.08 \\
\hline Fll:\#neg network members & .00 & 12.00 & 1.98 & 2.10 \\
\hline Fll:instrumental-pos-tot & .00 & 11.00 & 1.23 & 2.05 \\
\hline FII:instrumental-neg-tot & .00 & 7.00 & .29 & .85 \\
\hline FII:expressive-pos-tot & .00 & 12.00 & 5.82 & 4.10 \\
\hline FII:expressive-neg-tot & .00 & 9.00 & 1.70 & 1.79 \\
\hline FII: closeness-mean & .00 & 2.47 & .90 & .53 \\
\hline Fll:important-mean & .00 & 2.47 & .95 & .57 \\
\hline FIl:satisfaction-mean & .00 & 2.42 & .92 & .54 \\
\hline
\end{tabular}

$N=106$ 
Table 6

Correlations: Relation between original SIQ and Retest Data

\begin{tabular}{|c|c|c|c|}
\hline SIQ Item & Follow-up Group & Pearson & Significance level \\
\hline Total \# of supports & $\begin{array}{l}\text { 2-Day Follow-up } \\
\text { 2-Week Follow-up }\end{array}$ & $\begin{array}{l}r=.858 \\
r=.890\end{array}$ & $\begin{array}{l}p \leq .01 \\
p \leq .01\end{array}$ \\
\hline Frequency of Interactions & $\begin{array}{l}\text { 2-Day Follow-up } \\
\text { 2-Week Follow-up }\end{array}$ & $\begin{array}{l}r=.778 \\
r=.947\end{array}$ & $\begin{array}{l}p \leq .01 \\
p \leq .01\end{array}$ \\
\hline $\begin{array}{l}\text { Overall Positive Social } \\
\text { Interactions }\end{array}$ & $\begin{array}{l}\text { 2-Day Follow-up } \\
\text { 2-Week Follow-up }\end{array}$ & $\begin{array}{l}r=.918 \\
r=.850\end{array}$ & $\begin{array}{l}p \leq .01 \\
p \leq .01\end{array}$ \\
\hline $\begin{array}{l}\text { Overall Negative Social } \\
\text { Interactions }\end{array}$ & $\begin{array}{l}\text { 2-Day Follow-up } \\
\text { 2-Week Follow-up }\end{array}$ & $\begin{array}{l}r=.694 \\
r=.897\end{array}$ & $\begin{array}{l}p \leq .01 \\
p \leq .01\end{array}$ \\
\hline $\begin{array}{l}\text { Positive Socializing } \\
\text { Interactions }\end{array}$ & $\begin{array}{l}\text { 2-Day Follow-up } \\
\text { 2-Week Follow-up }\end{array}$ & $\begin{array}{l}r=.878 \\
r=.894\end{array}$ & $\begin{array}{l}p \leq .01 \\
p \leq .01\end{array}$ \\
\hline $\begin{array}{l}\text { Negative Socializing } \\
\text { Interactions }\end{array}$ & $\begin{array}{l}\text { 2-Day Follow-up } \\
\text { 2-Week Follow-up }\end{array}$ & $\begin{array}{l}r=.515 \\
r=.789\end{array}$ & $\begin{array}{l}p \leq .05 \\
p \leq .01\end{array}$ \\
\hline $\begin{array}{l}\text { Positive Tangible } \\
\text { Interactions }\end{array}$ & $\begin{array}{l}\text { 2-Day Follow-up } \\
\text { 2-Week Follow-up }\end{array}$ & $\begin{array}{l}r=.837 \\
r=.574\end{array}$ & $\begin{array}{l}p \leq .01 \\
p \leq .01\end{array}$ \\
\hline $\begin{array}{l}\text { Negative Tangible } \\
\text { Interactions }\end{array}$ & $\begin{array}{l}\text { 2-Day Follow-up } \\
\text { 2-Week Follow-up }\end{array}$ & $\begin{array}{l}r=.689 \\
r=.972\end{array}$ & $\begin{array}{l}p \leq .01 \\
p \leq .01\end{array}$ \\
\hline $\begin{array}{l}\text { Positive Cognitive } \\
\text { Guidance }\end{array}$ & $\begin{array}{l}\text { 2-Day Follow-up } \\
\text { 2-Week Follow-up }\end{array}$ & $\begin{array}{l}r=.963 \\
r=.922\end{array}$ & $\begin{array}{l}p \leq .01 \\
p \leq .01\end{array}$ \\
\hline $\begin{array}{l}\text { Negative Cognitive } \\
\text { Guidance }\end{array}$ & $\begin{array}{l}\text { 2-Day Follow-up } \\
\text { 2-Week Follow-up }\end{array}$ & $\begin{array}{l}r=.831 \\
r=.575\end{array}$ & $\begin{array}{l}p \leq .01 \\
p \leq .01\end{array}$ \\
\hline $\begin{array}{l}\text { Positive Emotional } \\
\text { Interactions }\end{array}$ & $\begin{array}{l}\text { 2-Day Follow-up } \\
\text { 2-Week Follow-up }\end{array}$ & $\begin{array}{l}r=.901 \\
r=.832\end{array}$ & $\begin{array}{l}p \leq .01 \\
p \leq .01\end{array}$ \\
\hline $\begin{array}{l}\text { Negative Emotional } \\
\text { Interactions }\end{array}$ & $\begin{array}{l}\text { 2-Day Follow-up } \\
\text { 2-Week Follow-up }\end{array}$ & $\begin{array}{l}r=.607 \\
r=.816\end{array}$ & $\begin{array}{l}p \leq .01 \\
p \leq .01\end{array}$ \\
\hline Take Advantage & $\begin{array}{l}\text { 2-Day Follow-up } \\
\text { 2-Week Follow-up }\end{array}$ & $\begin{array}{l}r=.613 \\
r=.803\end{array}$ & $\begin{array}{l}p \leq .01 \\
p \leq .01\end{array}$ \\
\hline Overprotective & $\begin{array}{l}\text { 2-Day Follow-up } \\
\text { 2-Week Follow-up }\end{array}$ & $\begin{array}{l}r=.926 \\
r=.874\end{array}$ & $\begin{array}{l}p \leq .01 \\
p \leq .01\end{array}$ \\
\hline Reciprocity & $\begin{array}{l}\text { 2-Day Follow-up } \\
\text { 2-Week Follow-up }\end{array}$ & $\begin{array}{l}r=.639 \\
r=.874\end{array}$ & $\begin{array}{l}p \leq .01 \\
p \leq .01\end{array}$ \\
\hline
\end{tabular}


Appendix A

Social Interactions Questionnaire (SIQ) 


\section{Appendix A}

\section{Social Interactions Questionnaire}

Sometimes the people we spend time with have an impact on how we feel. They may make us feel good when they spend time with us, listen when we need to talk, or help us with things we have trouble doing alone. Some people may make us feel bad when they say hurtful things, forget that we have plans, or take advantage of us. Sometimes people make us feel both good and bad at the same time. They might take us shopping to get something we need, but complain that we are a burden to them, making us feel good because we bought the items we needed, but bad because we felt like a burden.

Please list up to 10 people who influence how you feel whether you like them or not, and with whom you have some sort of contact. For example, these people may be family members, friends, neighbors, workmates, professionals (i.e. physician, therapist), etc. Please list people that make you feel good, bad, or both good and bad.

\begin{tabular}{|c|c|c|c|}
\hline & $\underline{\text { RELATION }}$ & \# OF INTERACTIONS & DOES THIS PERSON \\
\hline$\underline{\text { INITIALS }}$ & (e.g., friend, wife) & (e.g., daily, weekly) & LIVE WITH YOU? \\
\hline
\end{tabular}

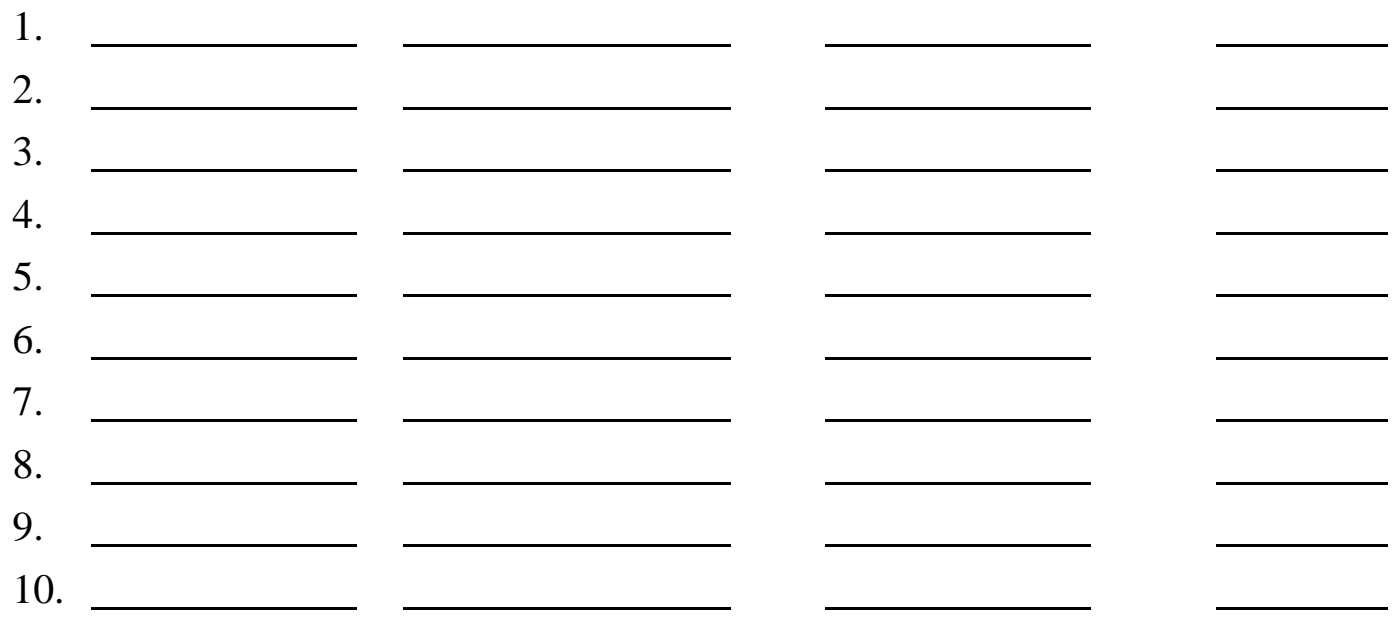

Please write the name of the person you listed next to \#1 on the top of the next page, then write the person you listed next to \#2 on the top of the second page, then write the name of the person listed nest to \#3 on the top of the third page, and so on until you have listed each name. Remember that you do not have list ten people.

Please answer each of the questions provided about the people you listed on the following pages. Please circle the answer that best fits how you feel about each person. If a question does not apply to a person, please circle " 1 " for that answer.

Thank you for your help in completing this questionnaire 
Person \#1

(please write the initials of the person you listed as \# 1 on this line and answer the following questions as they relate to this person)

Please use the following rating scale to answer each question:

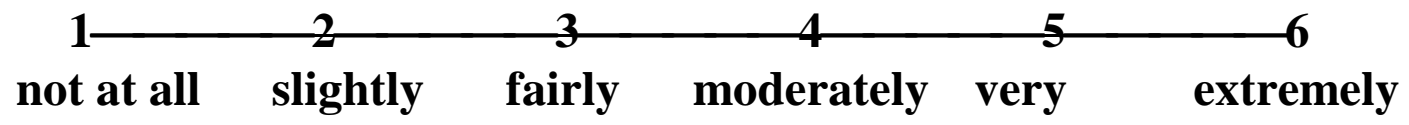

Circle the Number

that Best Applies

1. Being with this person socially (ex: recreation, conversation, having meals together)

how enjoyable is the person in these situations? ........

how upsetting or unsupportive is the person in these situations? $\quad \begin{array}{lllllll}1 & 2 & 3 & 4 & 5 & 6\end{array}$

2. Being helped by this person with chores or tasks

(ex: providing rides or financial assistance)

how helpful or supportive is the person in these situations? . . $\quad 1 \quad 1 \quad 2 \quad \begin{array}{llllll}3 & 4 & 5 & 6\end{array}$

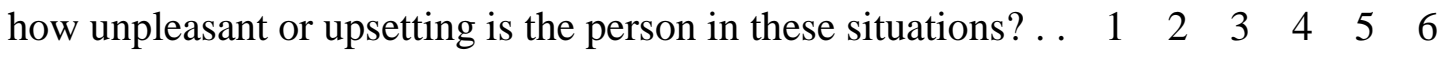

3. Being helped by this person in clearing up things that are

confusing or providing information (ex: legal or medical

advice, who to call to have your lawn cut).

how helpful or supportive is the person in these situations? . . $\quad 1 \quad 1 \quad 2 \quad \begin{array}{llllll} & 4 & 4 & 5 & 6\end{array}$

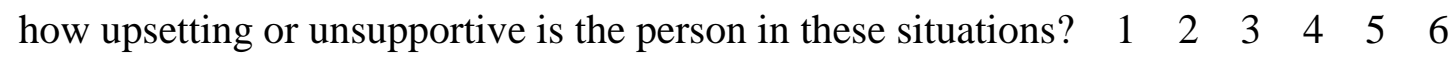

4. Receiving sympathy, caring, understanding, love, or

reassurance from this person.

how helpful or supportive is the person in these situations? . . $\quad 1 \quad 1 \quad 2 \quad \begin{array}{lllll}3 & 4 & 5 & 6\end{array}$

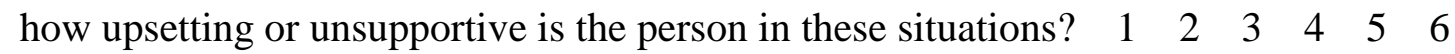

5. How much does this person take advantage of you (e.g.,

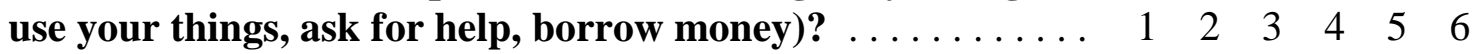

6. How overprotective is this person (e.g., does things for you that you would rather do for yourself, treat you like a child)? $\quad \begin{array}{llllll}2 & 2 & 3 & 4 & 5 & 6\end{array}$

7. How equal is your relationship (e.g., you both help each 
Psychometric Properties of the SIQ 58

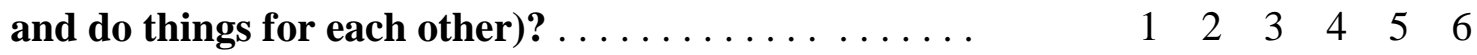


SIQ-Stressors

Please make a check mark next to each stressful event that you experienced within the past six months.

Please also write the date that you that each stressful event occurred.

$\square$ retirement date:

you moved to a new home date:

you moved to a new town date:

you became ill/injured date:

$\square$ financial difficulties date:

spouse became ill/injured date:

spouse moved into a nursing home date:

you have become the caretaker of your spouse date:

$\square$ death of friend date:

$\square$ death of spouse date:

death of a parent date:

$\square$ other specify:

date:

$\square$ other specify:

date:

other specify:

date: 


\section{Appendix B}

\section{Frequency of Interactions Interview}




\section{Appendix B}

FII

I would like to ask you some questions about people you have interacted with in the past 2 months. I will be asking about people who have been helpful to you during this time. I also will be asking about people who have not been very helpful. For each question I ask, you may name as many people as you wish. You may name your friends and family members, as well as your professional contacts, such as doctors, hospital staff, and ministers. For each person, I will ask for the initial of their name and their Relatnship to you, for example, your brother. I will use these initials later in the interview in order to gaher more information on each person you name. Remember that my questions are about the past 2 months only. First, I would like some information on the ways people have been helpful to you in this time.

(also obtain frequency of each type of interactions on a 5-point scale ranging from never to often)

$\begin{array}{ccccc}1 & 2 & 3 & 4 & 5 \\ \text { Never } & \text { Rarely } & \text { Ocasionally } & \text { Regularly } & \text { Often }\end{array}$

\section{Is there someone who:}

(I) $1 . \quad$ has helped you by running errands?

\begin{tabular}{|l|l|l|l|l|l|l|l|l|l|l|}
\hline Initials & & & & & & & & & & \\
\hline Relatn & & & & & & & & & & \\
\hline Frqncy & & & & & & & & & & \\
\hline
\end{tabular}

(E) 2. has said or done something to take your mind off your worries?

\begin{tabular}{|l|l|l|l|l|l|l|l|l|l|l|}
\hline Initials & & & & & & & & & & \\
\hline Relatn & & & & & & & & & & \\
\hline Frqncy & & & & & & & & & & \\
\hline
\end{tabular}

(E) 3. has given you information that made you feel less anxious?

\begin{tabular}{|l|l|l|l|l|l|l|l|l|l|l|}
\hline Initials & & & & & & & & & & \\
\hline Relatn & & & & & & & & & & \\
\hline Frqncy & & & & & & & & & & \\
\hline
\end{tabular}

(E) 4. has made helpful suggestions about how you might adjust your way of doing everyday activities?

\begin{tabular}{|l|l|l|l|l|l|l|l|l|l|l|}
\hline Initials & & & & & & & & & & \\
\hline Relatn & & & & & & & & & & \\
\hline Frqncy & & & & & & & & & & \\
\hline
\end{tabular}

(E) 5. has said or done something to encourage you to feel better? 


\begin{tabular}{|l|l|l|l|l|l|l|l|l|l|l|}
\hline Initials & & & & & & & & & & \\
\hline Relatn & & & & & & & & & & \\
\hline Frqncy & & & & & & & & & & \\
\hline
\end{tabular}

(I) 6. helps you with personal care activities?

\begin{tabular}{|l|l|l|l|l|l|l|l|l|l|l|}
\hline Initials & & & & & & & & & & \\
\hline Relatn & & & & & & & & & & \\
\hline Frqncy & & & & & & & & & & \\
\hline
\end{tabular}

(I) 7. helps you with other activities of daily living?

\begin{tabular}{|l|l|l|l|l|l|l|l|l|l|l|}
\hline Initials & & & & & & & & & & \\
\hline Relatn & & & & & & & & & & \\
\hline Frqncy & & & & & & & & & & \\
\hline
\end{tabular}

(E) $8 . \quad$ has helped you by listening to your feelings?

\begin{tabular}{|l|l|l|l|l|l|l|l|l|l|l|}
\hline Initials & & & & & & & & & & \\
\hline Relatn & & & & & & & & & & \\
\hline Frqncy & & & & & & & & & & \\
\hline
\end{tabular}

(E) 9. has said or done something to make you feel comfortable about the way you look?

\begin{tabular}{|l|l|l|l|l|l|l|l|l|l|l|}
\hline Initials & & & & & & & & & & \\
\hline Relatn & & & & & & & & & & \\
\hline Frqncy & & & & & & & & & & \\
\hline
\end{tabular}

Now I would like to ask you about some things people may have said or done that were not helpful. Some of the people who did helpful things may also have done things that were not so helpful. I am concerned with how their actions affected you, and not whether the person intended for their actions to have such an impact.

(E) 10. Have you talked to someone who's been in a situation similar to yours? Did this discussion make you feel more comfortable w/your own feelings? (If yes, code as support. If no, code as problematic.)

\begin{tabular}{|l|l|l|l|l|l|l|l|l|l|l|}
\hline Initials & & & & & & & & & & \\
\hline Relatn & & & & & & & & & & \\
\hline Frqncy & & & & & & & & & & \\
\hline
\end{tabular}

Is there someone who:

(I) 11. has proved not to be dependable in running errands? 


\begin{tabular}{|l|l|l|l|l|l|l|l|l|l|l|}
\hline Initials & & & & & & & & & & \\
\hline Relatn & & & & & & & & & & \\
\hline Frqncy & & & & & & & & & & \\
\hline
\end{tabular}

(E) 12. has said or done something that made you feel worried and upset?

\begin{tabular}{|l|l|l|l|l|l|l|l|l|l|l|}
\hline Initials & & & & & & & & & & \\
\hline Relatn & & & & & & & & & & \\
\hline Frqncy & & & & & & & & & & \\
\hline
\end{tabular}

(E) 13. has given you information so that you felt more upset and worried?

\begin{tabular}{|l|l|l|l|l|l|l|l|l|l|l|}
\hline Initials & & & & & & & & & & \\
\hline Relatn & & & & & & & & & & \\
\hline Frqncy & & & & & & & & & & \\
\hline
\end{tabular}

(E) 14. has given you unwanted advice about how you should change your ways of doing everyday activities?

\begin{tabular}{|l|l|l|l|l|l|l|l|l|l|l|}
\hline Initials & & & & & & & & & & \\
\hline Relatn & & & & & & & & & & \\
\hline Frqncy & & & & & & & & & & \\
\hline
\end{tabular}

(E) 15. has said or done something that has discouraged you from getting better?

\begin{tabular}{|l|l|l|l|l|l|l|l|l|l|l|}
\hline Initials & & & & & & & & & & \\
\hline Relatn & & & & & & & & & & \\
\hline Frqncy & & & & & & & & & & \\
\hline
\end{tabular}

(I) 16. has assisted you with personal care activities when you would have preferred to have done there things by yourself?

\begin{tabular}{|l|l|l|l|l|l|l|l|l|l|l|}
\hline Initials & & & & & & & & & & \\
\hline Relatn & & & & & & & & & & \\
\hline Frqncy & & & & & & & & & & \\
\hline
\end{tabular}

(I) 17. has assisted you in other activities of daily living when you would have preferred to have done these things by yourself?

\begin{tabular}{|l|l|l|l|l|l|l|l|l|l|}
\hline Initials & & & & & & & & & \\
\hline
\end{tabular}




\begin{tabular}{|l|l|l|l|l|l|l|l|l|l|l|}
\hline Relatn & & & & & & & & & & \\
\hline Frqncy & & & & & & & & & & \\
\hline
\end{tabular}

(E) 18. seems unable to share feelings with you?

\begin{tabular}{|l|l|l|l|l|l|l|l|l|l|l|}
\hline Initials & & & & & & & & & & \\
\hline Reltin & & & & & & & & & & \\
\hline Frqncy & & & & & & & & & & \\
\hline
\end{tabular}

(I) 19. has said or done something that made you feel uncomfortable about the way you look?

\begin{tabular}{|l|l|l|l|l|l|l|l|l|l|l|}
\hline Initials & & & & & & & & & & \\
\hline Relatn & & & & & & & & & & \\
\hline Frqncy & & & & & & & & & & \\
\hline
\end{tabular}

Now I want to ask you some additional questions about the people you interact with. Remember that each of these questions are about the past 2 months only. For each of these questions, I want you to answer with the following 4-point scale ( $1=$ not at all, $4=$ extremely).

$\begin{array}{cccc}1 & 2 & 3 & 4 \\ \text { Not at all } & \text { A little } & \text { Somewhat } & \text { Extremely }\end{array}$

Questions are asked about each social network member listed above.

How satisfied are you with your Relatnship with

How close do you feel to ?

How important is your Relatnship with to you?

\begin{tabular}{|l|l|l|l|}
\hline Network Member & satisfied & close & important \\
\hline & & & \\
\hline & & & \\
\hline & & & \\
\hline & & & \\
\hline & & & \\
\hline & & & \\
\hline & & & \\
\hline & & & \\
\hline
\end{tabular}




\section{Appendix C}

Demographics Questionnaire 
Appendix C

\section{Demographic Information}

Date of birth:

Sex: $\quad \square$ male $\quad \square$ female

\section{Marital status:}

$\square$ married $\square$ single $\square$ widowed $\square$ separated $\square$ divorced $\square$ other

Living situation:

$\square$ alone $\quad \square$ with spouse $\quad \square$ with family $\quad \square$ other

How many of your children live within a 1-hour drive of your home?

How many of your grandchildren live within a 1-hour drive of your

home?

How many other relatives (siblings, nieces, nephews) live within a 1drive of your home?

Physical health:

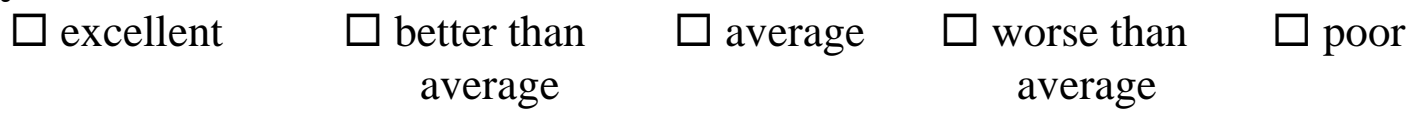

Ethnicity:

$\square$ Caucasian $\quad \square$ African American $\quad \square$ Latino American $\quad \square$ Asian American

$\square$ other

Are you currently employed? $\square$ yes $\square$ no retired? $\square$ yes $\square$ no

disabled $\square$ yes $\square$ no

other $\quad \square$ yes $\square$ no please specify:

What is the highest grade you completed in school? 
Appendix D

Contact Form 


\section{Appendix D}

\section{Contact Form}

Please indicate your name and address so that we can contact you if you have won $\$ 50.00$ for your participation in this study. This information will be kept separate from your responses to questionnaires.

Name

\begin{tabular}{ll}
\hline Address & Apt. \#
\end{tabular}

City

State

Zip Code

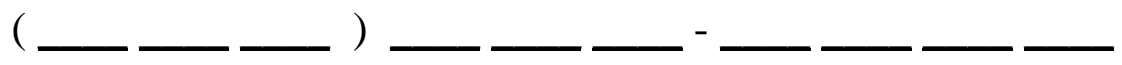

Phone Number 
Appendix E

Correlations: SIQ and Measures of Mental Health 


\section{Appendix E}

Correlations: SIQ and Measures of Mental Health

\begin{tabular}{|l|l|l|}
\hline & BDI & LSI \\
\hline NSI: SIQ & $.397^{\star \star}$ & $-.217^{\star}$ \\
& .000 & .025 \\
\hline Social: NSI SIQ & $.383^{\star \star}$ & $-.260^{\star *}$ \\
& .000 & .007 \\
\hline Tangible: NSI SIQ & $.324^{\star \star}$ & -.132 \\
& .001 & .177 \\
\hline Cognitive: NSI SIQ & .181 & -.125 \\
& .063 & .200 \\
\hline Emotional: NSI SIQ & $.239^{*}$ & -.078 \\
& .013 & .427 \\
\hline Take Advantage: SIQ & $.241^{*}$ & -.155 \\
& .013 & .112 \\
\hline Overprotective: SIQ & .053 & -.095 \\
& .592 & .332 \\
\hline Reciprocity: SIQ & -.051 & -.058 \\
& .603 & .555 \\
\hline
\end{tabular}

$\mathrm{n}=106$ for all cases

${ }^{* *}=$ Correlation is significant at the 0.01 level (2-tailed)

* $=$ Correlation is significant at the 0.05 level (2-tailed) 
Appendix F

Correlations: Relation between SIQ and FII 


\section{Appendix $\mathrm{F}$}

Correlations: Relation between SIQ and FII

\begin{tabular}{|c|c|c|c|c|c|c|c|c|c|c|c|}
\hline & $\begin{array}{l}\# \\
\stackrel{\#}{+} \\
\stackrel{+}{\overline{1}}\end{array}$ & 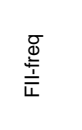 & $\begin{array}{l}\text { O } \\
\stackrel{ \pm}{ \pm} \\
\stackrel{+}{+} \\
\stackrel{+}{\bar{\Psi}}\end{array}$ & $\begin{array}{l}\ddot{0} \\
\stackrel{0}{0} \\
\stackrel{0}{1} \\
\stackrel{\overline{1}}{\overline{1}}\end{array}$ & 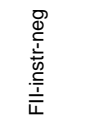 & 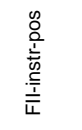 & 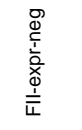 & $\begin{array}{l}00 \\
0 \\
\frac{0}{1} \\
\frac{1}{\alpha} \\
0 \\
\frac{1}{\overline{1}} \\
\end{array}$ & 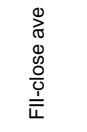 & 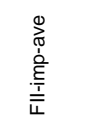 & 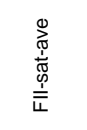 \\
\hline & $.549^{\star \star}$ & .021 & $.416^{\star \star}$ & $.432^{\star *}$ & .168 & $.369^{* \star}$ & $.384^{\star \star}$ & $.396^{* \star}$ & $.240^{*}$ & $.268^{\star \star}$ & $.263^{* \star}$ \\
\hline \multirow[t]{3}{*}{ 1. SIQ: tot \# } & .000 & .832 & .000 & .000 & .492 & .004 & .001 & .000 & .015 & .007 & .008 \\
\hline & 106 & 102 & 78 & 99 & 19 & 59 & 76 & 94 & 102 & 102 & 102 \\
\hline & .047 & $.456^{\star \star}$ & .076 & .132 & .037 & .152 & .115 & .120 & -.097 & $\begin{array}{l}.171 \\
\end{array}$ & -.068 \\
\hline \multirow[t]{3}{*}{ 2. SIQ-freq } & .633 & .000 & .509 & .192 & .881 & .251 & .324 & .250 & .334 & .086 & .499 \\
\hline & 106 & 102 & 78 & 99 & 19 & 59 & 76 & 94 & 102 & 102 & 102 \\
\hline & -.012 & .091 & -.029 & -.090 & -.161 & -.132 & -.035 & -.058 & -.175 & $-.197^{*}$ & $-.321^{* *}$ \\
\hline \multirow[t]{3}{*}{ 3. SIQ-\# neg } & .901 & .365 & .804 & .377 & .510 & .317 & .764 & .581 & .079 & .047 & .001 \\
\hline & 106 & 102 & 78 & 99 & 19 & 59 & 76 & 94 & 102 & 102 & 102 \\
\hline & $.408^{\text {** }}$ & .098 & $.363^{* *}$ & $.361^{* \star}$ & .400 & $.334^{* *}$ & $.324^{* *}$ & $.318^{* *}$ & $.368^{* *}$ & $.354^{\star \star}$ & $.343^{\text {** }}$ \\
\hline \multirow[t]{3}{*}{ 4. SIQ-\# pos } & .000 & .326 & .001 & .000 & .090 & .010 & .004 & .002 & .000 & .000 & .000 \\
\hline & 106 & 102 & 78 & 99 & 19 & 59 & 76 & 94 & 102 & 102 & 102 \\
\hline & .057 & .109 & $.254^{*}$ & .006 & .309 & .037 & $.282 *$ & .005 & .038 & .046 & -.070 \\
\hline \multirow[t]{3}{*}{ 5. SIQ-soc-neg-tot } & .559 & .274 & .025 & .950 & .198 & .781 & .014 & .960 & .703 & .644 & .487 \\
\hline & 106 & 102 & 78 & 99 & 19 & 59 & 76 & 94 & 102 & 102 & 102 \\
\hline & $.476^{\star \star}$ & .085 & $.399^{\star \star}$ & $.391^{\star \star}$ & .239 & $.280^{*}$ & $.354^{\star \star}$ & $.391^{\star \star}$ & $.333^{\text {** }}$ & $.298^{\star \star}$ & $.329^{\star \star}$ \\
\hline \multirow[t]{3}{*}{ 6. SIQ-soc-pos-tot } & .000 & .396 & .000 & .000 & .324 & .032 & .002 & .000 & .001 & .002 & .001 \\
\hline & 106 & 102 & 78 & 99 & 19 & 59 & 76 & 94 & 102 & 102 & 102 \\
\hline & -.021 & -.011 & .052 & -.067 & -.088 & -.098 & .067 & $.238^{*}$ & .048 & -.026 & -.130 \\
\hline \multirow[t]{3}{*}{ 7. SIQ-tan-neg-tot } & .832 & .909 & .653 & .511 & .721 & .459 & .567 & .021 & .630 & .798 & .194 \\
\hline & 106 & 102 & 78 & 99 & 19 & 59 & 76 & 94 & 102 & 102 & 102 \\
\hline & $.294^{\star \star}$ & .052 & $.418^{* \star}$ & $.311^{* *}$ & $.621^{\star \star}$ & $.260^{*}$ & $.355^{\text {** }}$ & $.277^{* *}$ & $.229^{*}$ & $.235^{*}$ & .176 \\
\hline \multirow[t]{3}{*}{ 8. SIQ-tan-pos-tot } & .002 & .603 & .000 & .002 & .005 & .047 & .002 & .007 & .021 & .017 & .077 \\
\hline & 106 & 102 & 78 & 99 & 19 & 59 & 76 & 94 & 102 & 102 & 102 \\
\hline & .024 & .039 & $.294^{\star \star}$ & -.015 & .376 & -.001 & $.248^{*}$ & -.013 & .124 & .111 & -.023 \\
\hline \multirow[t]{3}{*}{ 9. SIQ-cog-neg-tot } & .804 & .697 & .009 & .880 & .113 & .995 & .031 & .902 & .213 & .266 & .820 \\
\hline & 106 & 102 & 78 & 99 & 19 & 59 & 76 & 94 & 102 & 102 & 102 \\
\hline & .064 & .061 & $.381^{\star *}$ & .079 & .454 & -.044 & $.338^{* *}$ & .064 & .156 & .143 & .164 \\
\hline \multirow[t]{3}{*}{ 10. SIQ-cog-pos-tot } & .512 & .541 & .001 & .438 & .051 & .739 & .003 & .539 & .118 & .151 & .100 \\
\hline & 106 & 102 & 78 & 99 & 19 & 59 & 76 & 94 & 102 & 102 & 102 \\
\hline & .028 & .128 & .095 & -.095 & -.177 & -.045 & .090 & -.112 & -.047 & -.100 & $-.212^{*}$ \\
\hline \multirow[t]{3}{*}{ 11. SIQ-emot-neg-tot } & .777 & .200 & .408 & .351 & .468 & .736 & .438 & .282 & .637 & .315 & .032 \\
\hline & 106 & 102 & 78 & 99 & 19 & 59 & 76 & 94 & 102 & 102 & 102 \\
\hline & $.532^{\star \star}$ & .037 & $.349^{\star \star}$ & $.410^{* *}$ & .280 & $.319^{*}$ & $.311^{\text {** }}$ & $.381^{\star \star}$ & $.348^{* \star}$ & $.368^{* \star}$ & $.336^{* \star}$ \\
\hline \multirow[t]{3}{*}{ 12. SIQ-emot-pos-tot } & .000 & .709 & .002 & .000 & .246 & .014 & .006 & .000 & .000 & .000 & .001 \\
\hline & 106 & 102 & 78 & 99 & 19 & 59 & 76 & 94 & 102 & 102 & 102 \\
\hline & .050 & .001 & -.086 & .049 & .066 & $.278^{*}$ & -.069 & -.008 & $.305^{* *}$ & $.315^{* \star}$ & $.367^{* \star}$ \\
\hline \multirow[t]{3}{*}{ 13. SIQ-reciprocal-ave } & .609 & .990 & .456 & .627 & .788 & .033 & .552 & .937 & .002 & .001 & .000 \\
\hline & 106 & 102 & 78 & 99 & 19 & 59 & 76 & 94 & 102 & 102 & 102 \\
\hline & .060 & .077 & .159 & -.034 & .379 & -.050 & .132 & -.055 & .047 & -.024 & -.069 \\
\hline \multirow[t]{3}{*}{ 14. SIQ-overprotect-ave } & .542 & .443 & .164 & .736 & .109 & .706 & .256 & .598 & .640 & .807 & .493 \\
\hline & 106 & 102 & 78 & 99 & 19 & 59 & 76 & 94 & 102 & 102 & 102 \\
\hline & -.071 & .143 & .043 & -.156 & .164 & -.067 & .044 & -.170 & $-.301^{\star \star}$ & $-.379^{* \star}$ & $-.471^{\star \star}$ \\
\hline \multirow[t]{2}{*}{ 15. SIQ-exploitative-ave } & .467 & .151 & .709 & .124 & .502 & .615 & .708 & .102 & .002 & .000 & .000 \\
\hline & 106 & 102 & 78 & 99 & 19 & 59 & 76 & 94 & 102 & 102 & 102 \\
\hline
\end{tabular}

**. Correlation is significant at the 0.01 level (2-tailed).

*. Correlation is significant at the 0.05 level (2-tailed). 


\section{Kimberly D. Kalish}

E-mail Address: kimberdk@aol.com

\section{EXPERIENCE}

EDUCATION

\section{Direct Service Experience}

1993 - present

- Conduct empirically based treatments based upon diagnoses and individual needs

- Execute assessments (e.g., intelligence, personality, functional, neuropsychological)

- Develop treatment plans, behavior modification plans, and evaluate outcomes patient populations:

- Older Adults

- Developmentally Disabled Adults

- Adults with Chronic Pain

- Survivors of Trauma

- Psychiatric Patients

- College Students

- Children with Behavior Disorders

- Brain Injured Patients

- Patients with Sexual Dysfunctions

- Hospital Staff settings:

- Nursing Homes, Home Care

- Outpatient Mental Health

- Behavioral Medicine Clinic

- VA Hospital

- Psychiatric Hospitals

- University Counseling Center/Clinic

- Hospice

- Private Practice

- Sexual Dysfunctions Clinic

- Day Treatment Center

\section{Teaching}

1992 - present

- Facilitate workshops on sensory deficits, dementia, bereavement, assertiveness, anger management, stress reduction, communication, crisis intervention

- Supervise and train clinical students and research assistants

\section{Program Evaluation/Consultation}

1993 - present

- Develop and facilitate team building exercises to improve morale and staff retention

- Train interdisciplinary team members to maximize quality of service delivery

- Utilize work groups to improve team dynamics and direct service provision

\section{Management}

1991 - present

- Oversee private practice during extended absence of executive director

- Supervise staff, develop departmental policy, provide monthly clinical reports

- Direct a community service organization with more than 500 volunteers

Palo Alto VA • Palo Alto, California (8/98 - 9/99)

- Clinical Psychology Internship in Geropsychology and Interprofessional Teams West Virginia University • Morgantown, West Virginia

- Doctorate in Clinical Psychology (1997 - 2001)

- Gerontology Certificate (1997)

- Master of Arts in Clinical Psychology (1993-1996)

State University of New York at Buffalo • Buffalo, New York (1989-1993)

- Bachelor of Arts in Psychology 